\title{
تأثير عرض النقود وسعر الصرف على التضخم في الاقتصاد اليبي
}

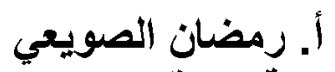 \\ باحث/ جامعة المرقب المبان
}

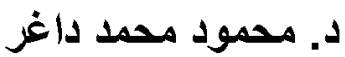 \\ جامعة بغداد- كلية الادارة والاقتصاد داغل \\ قسم الاقتصناد
}

تهذف هذه اللراسة إلى محاولة التعرف على الثر كل من عرض النقود وسعر الصرف على معدل

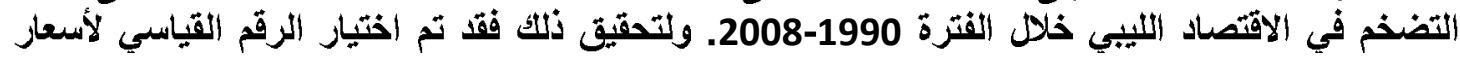

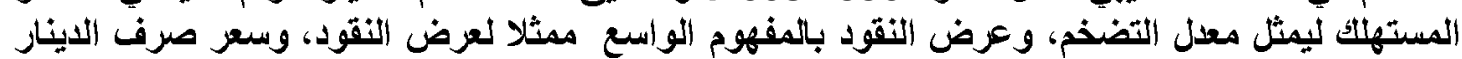

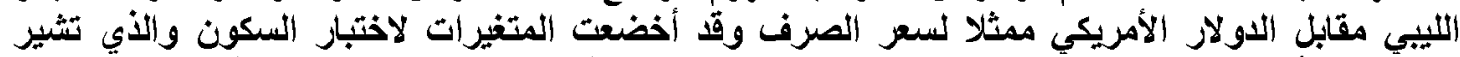

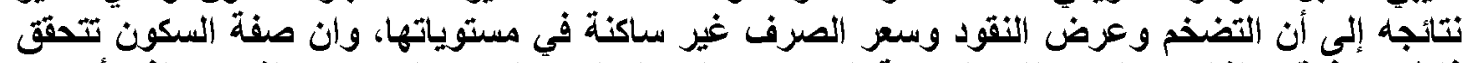

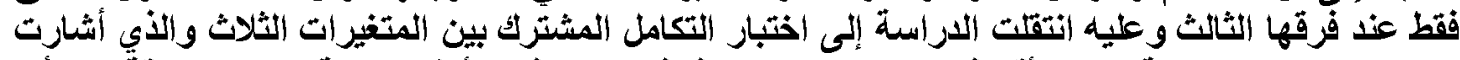

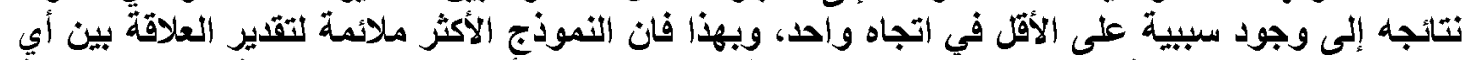

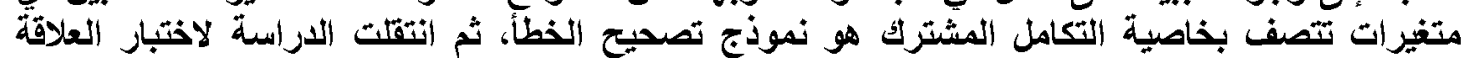
الالبيبية بين التضخم وكل من عرض النقود بالمغنى الواسع وسعر الصرف اللينار الليبي مقابل الدولار

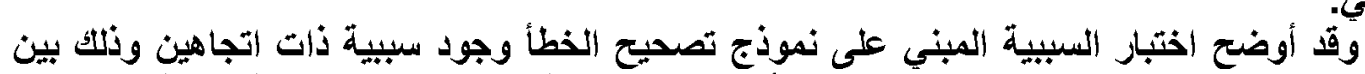

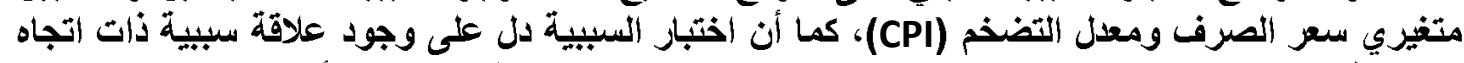

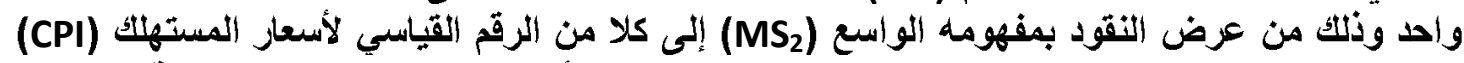

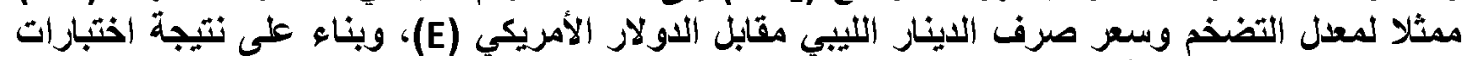

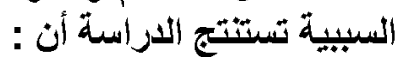

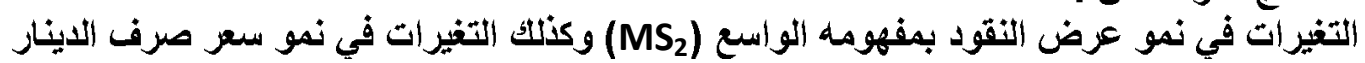
الليبي مقوما بالدولار الأمريكي (خفض قيمضته) تساعد في تفسير التفير التغيرات في نمو معدل التضخم في الأجلين

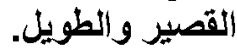




\section{Abstract:}

Economists believe that the rate of domestic inflation is mainly determined by several factors including money supply and exchange rate، where the money supply is clearly related and linked to monetary base (HB). They also think that the impact of exchange rate on money supply can be explained particularly through the mechanism of the movements in the balance of payments and foreign assets.

The aim of this study is to find out the impact of the fluctuations in money supply and exchange rate on the rate of domestic inflation in the Libyan economy. The study tries to contribute to the literature by examining the effects of money supply and exchange rate on the rate of domestic inflation in the Libyan economy during the period of 1990-2008.

The study divided into four sections، following the introduction' section two gives a brief review of the relationship between the inflation rate، money supply and exchange rate based on the economic theory. It also، attempts to address the issue of stabilized function of the demand for money and the main determinants of the exchange rate based on thoughts of variety of economic schools (e.g. classical and new-classical schools).

Section three gives a descriptive analysis of relationship between the inflation rate، money supply and exchange rate in the Libyan economy. Further' the money supply (in its wide $\left(\mathbf{M S}_{2}\right)$ and narrow $\left(\mathrm{MS}_{1}\right)$ concept) and exchange rate are determined and explained in this chapter in order to give the theoretical background for the following chapter.

Sophisticated economic models and econometric techniques have been utilized in Section four in order to achieve the main objectives of this study. These models and techniques include Error correction model (ECM) and Granger Causality model. The Error Correction Model is developed and tested in this chapter in order to analyze the long and short run relationship among the rate of inflation' money supply and exchange rate in the Libyan economy during the period 1990-2008. Furthermore' a two-way causality between the variables of the exchange rate and inflation (CPI)، has been tested using the methodology of Granger causality test in this chapter in order to determine the causation or the direction between these variables.

The main results of this study are illustrated in Section four. These results indicate that a two-way causality between exchange rate and inflation represented by consumer price index (CPI) occurred and found to be statistically significant. The result of Error correction model (ECM) shows that there is a long and short relationship among the variables under investigation. Furthermore The granger causality test indicates that the presence of a causal relationship with one direction from the money supply in its broad definition $\left(\mathrm{MS}_{2}\right)$ to consumer price index $(\mathrm{CPI})$ and the exchange rate of the Libyan dinar against the U.S. dollar (E).

Accordingly ، money supply $\left(\mathrm{MS}_{2}\right)$ and the exchange rate of the Libyan dinar are the main determinants of the rate of inflation in the Libyan economy in the short and long term 


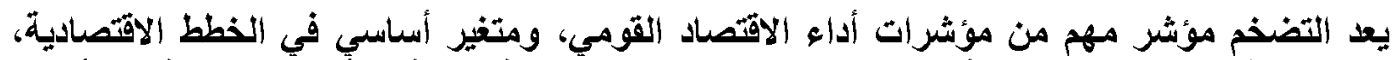

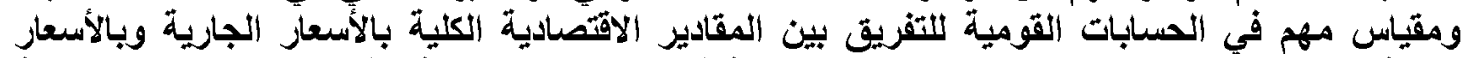

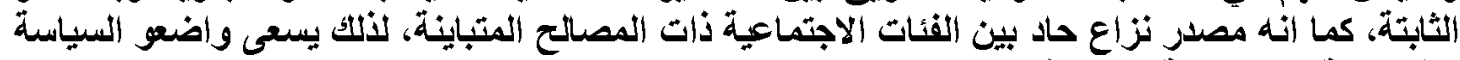

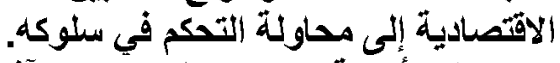

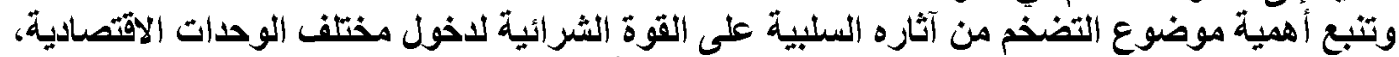
المخلية.

ورلا يزال الخلاف بين المدارس الاقتصادية قائما حول محددات التضخم ويشكل خاص حول مدى أهمية كل

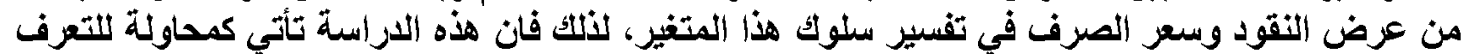
على تأثير كل من عرض النقود وسعر الصرف على سلوف فلك معدل التضخم في الاقتصاد الليبي.

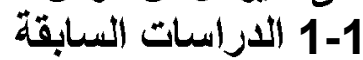

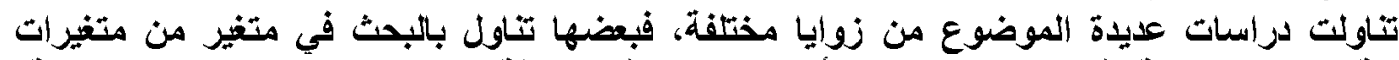

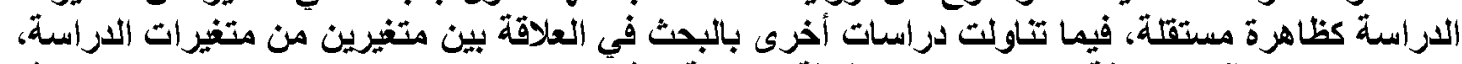

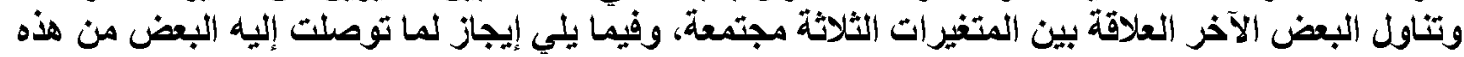

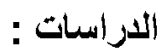

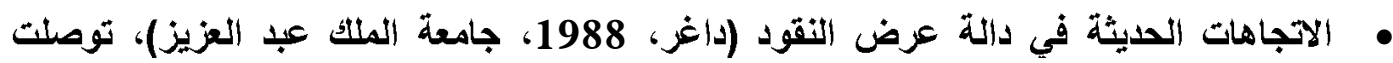

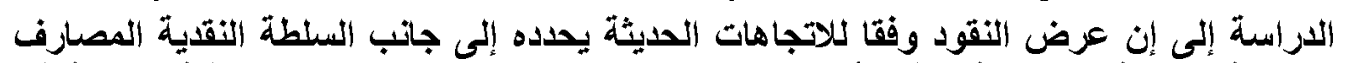

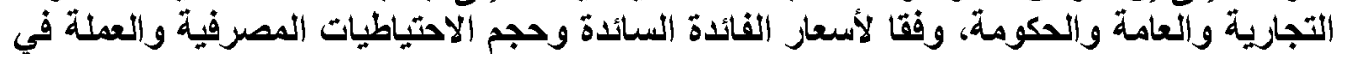
التداول.

لدراسة لمحددات التضخم بالكويت خلال الفترة 2004-1972 (العمر، 2007، جامعة عبد العزيز):

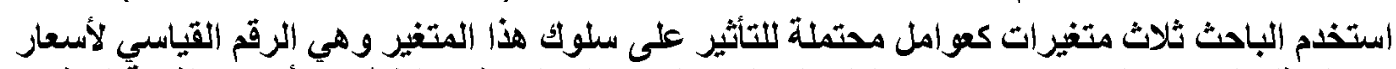

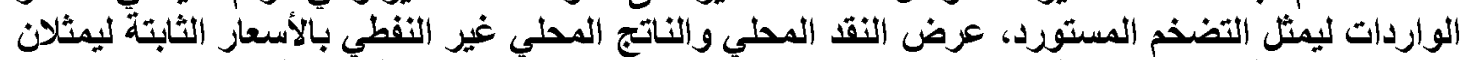

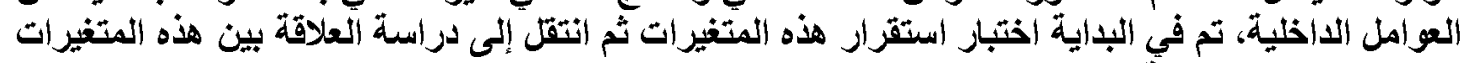
باستخدام اختبار السببية.

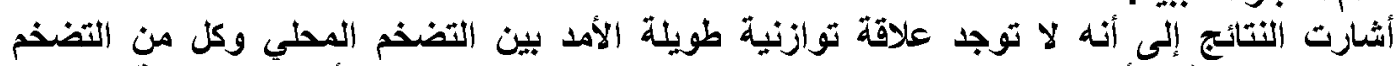

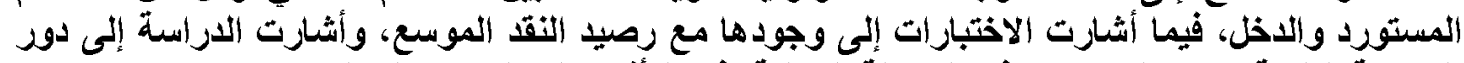

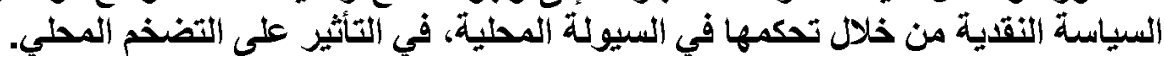

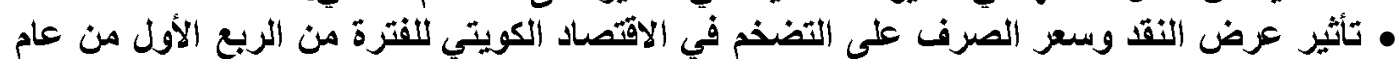

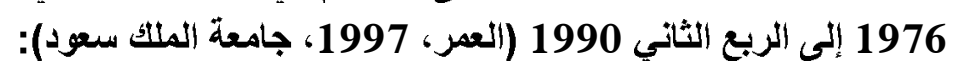

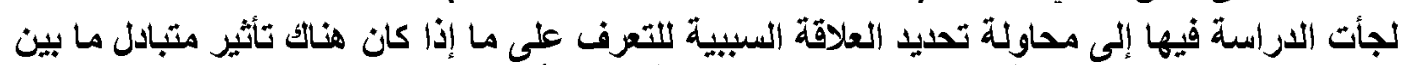

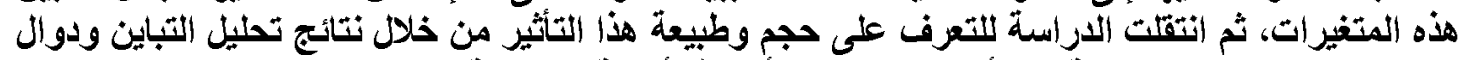

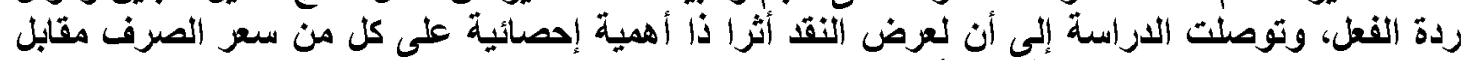

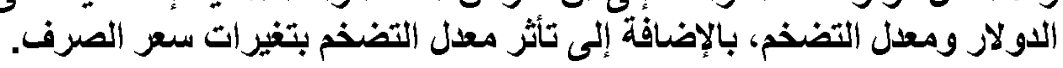

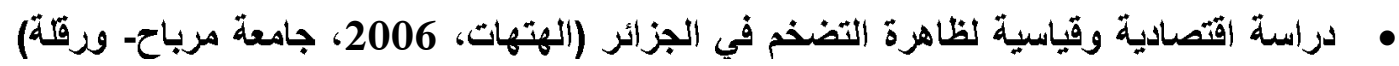

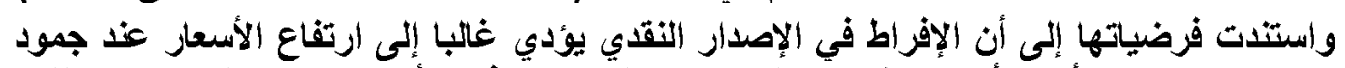

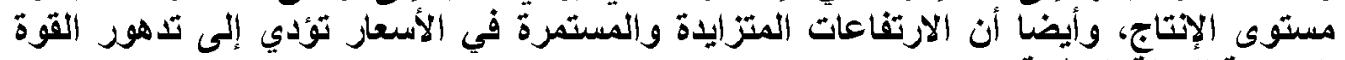
الشرائية للعملة الوطنية.

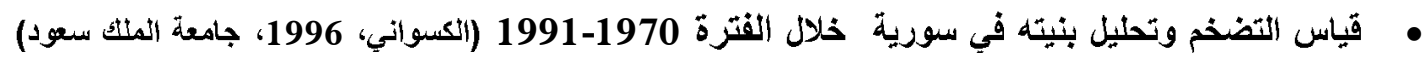

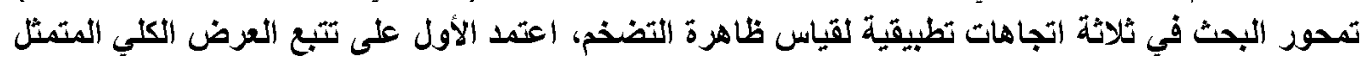

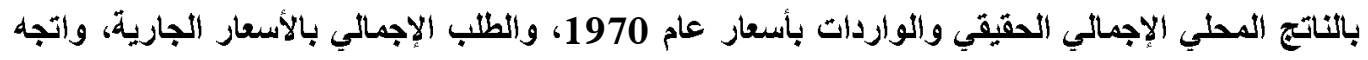

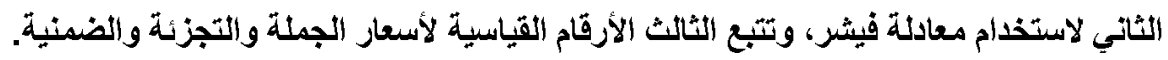


161

$$
\text { حدة }
$$

توصلت الدراسة إلى أن زيادة كل وحدة من الكتة النقاية المتداولة تؤدي إلى ارتفاع قدره 0.169 وحدة من الناتج المحلي الإجمالي الحقيقي، كما أن مرونة الأخير بالنسبة للكتة النقدية المتداولة

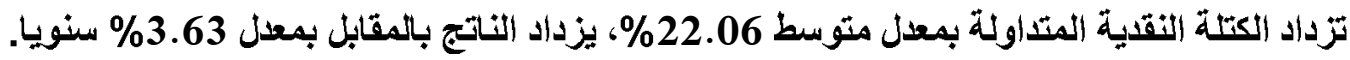
2-1 المشكلة البحثية

سجل الاقتصاد الليبي معدلات مرتفعة للتضخم خلال فترة الدراسة (1990-2008)، قفّ أشارت دراسة

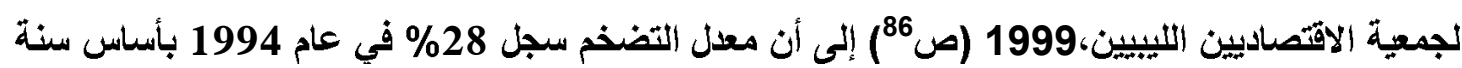
1980. وفي دراسة أخرى عن الهيئة العامة للمعلومات والتوثيق، (التقرير الأول حول التضخم في الاقتصاد

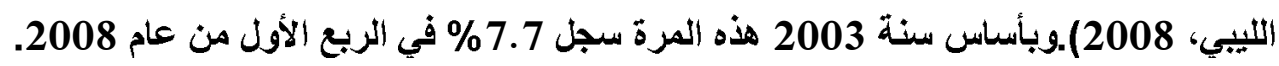

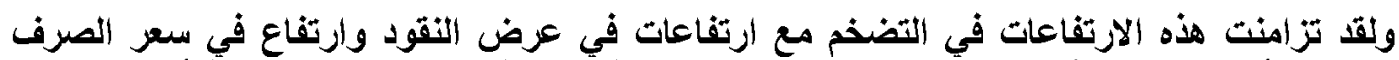

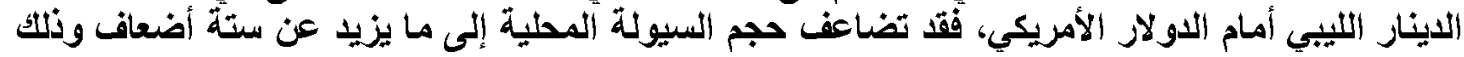

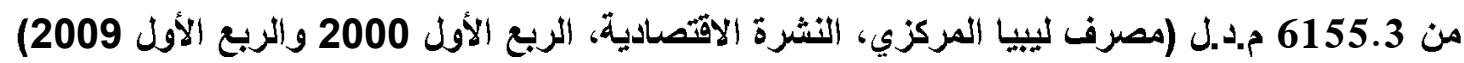
في عام 1990 إلى 37151.4 م.د.ل في عام 2008، وسجل الاينار الليبي نموا في سعر صرفه أمام ألام

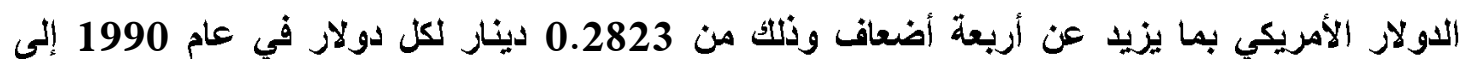

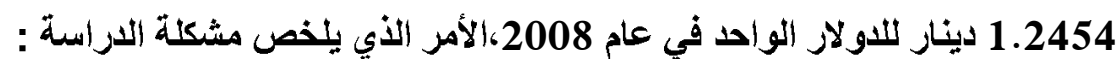

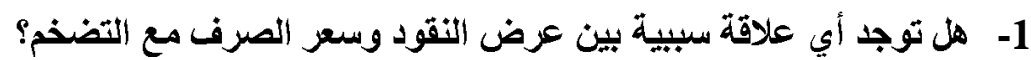

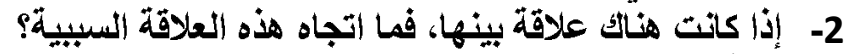

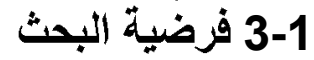

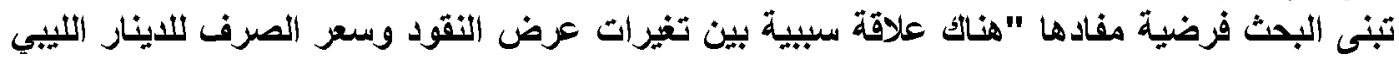

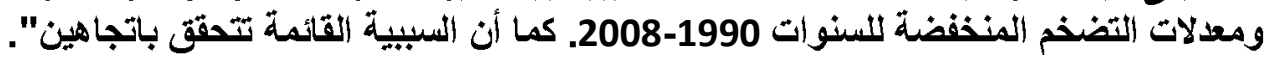

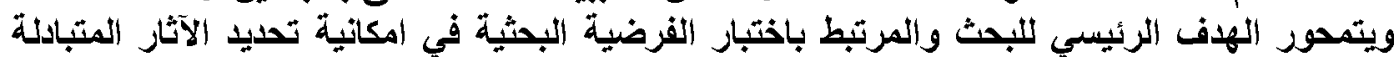

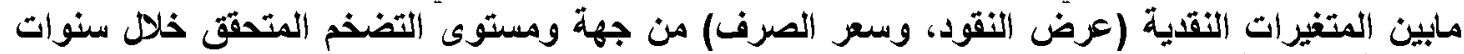

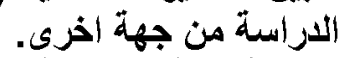

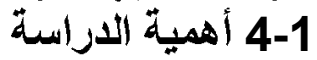

تتأثر دخول شريحة كبيرة من أفراد المجتمع الليبي، ويالأخص أصحاب المعاشات الأساسية والمرتبات

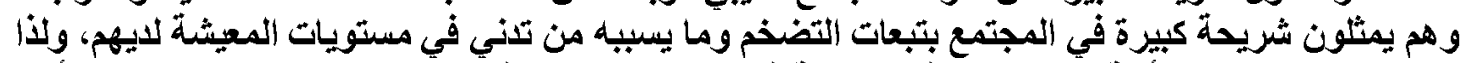

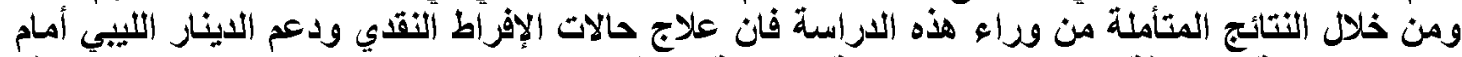

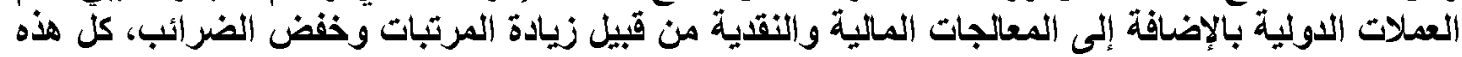

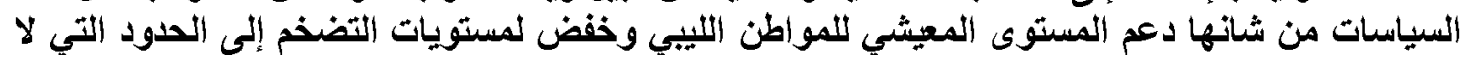
تضر مختلف شرائح المجتمع. دم: 1-1 5نهجية البحث وبنيته

يحاول الباحثان تتبع منهج المدرسة النقلية في تقليل العلاقة مابين المتغيرات المستهدفة، ولذلك يقترن

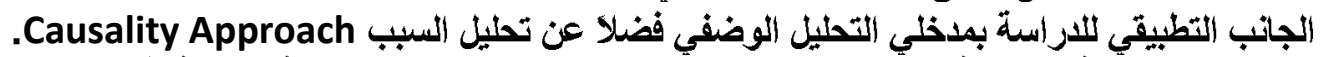

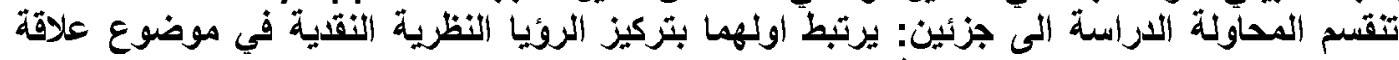

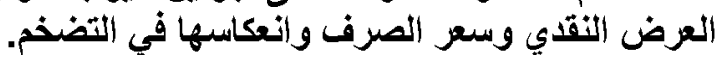

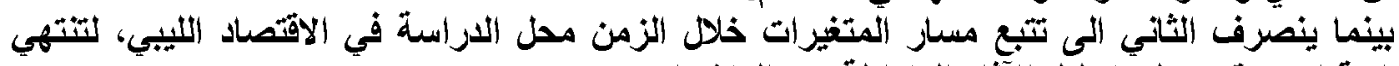
باختبار قياسي يقوم على تحليل الآثار المتبادلة بين المتغيرات التئن 


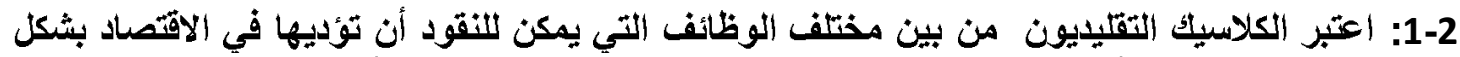

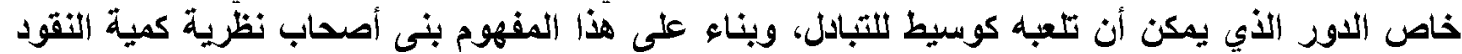

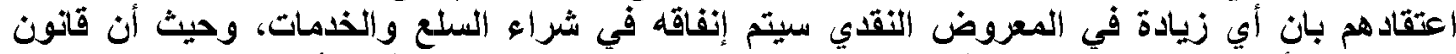

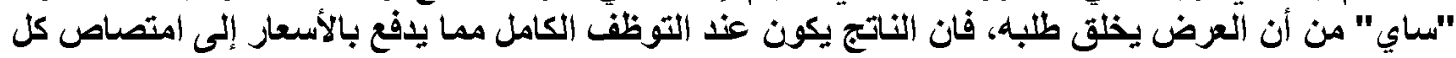

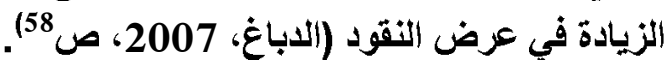
في نظرية تفضيل السيولة Liquidity preference حدد "كنز" متثير سعر الفائدة للتعبير عن العائد

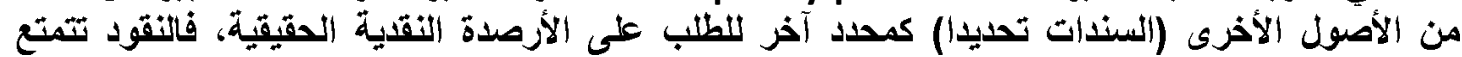

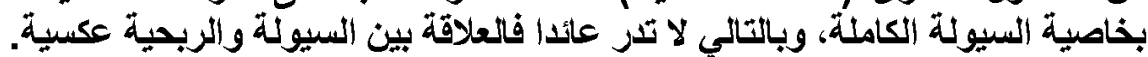

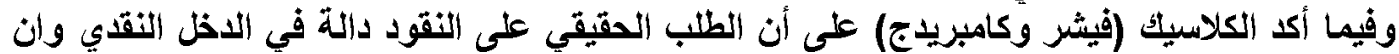

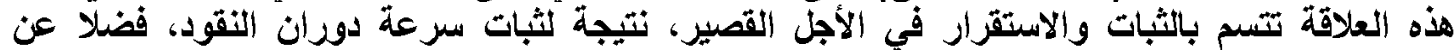

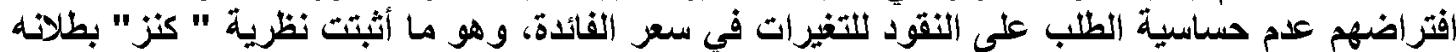

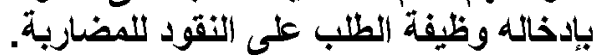

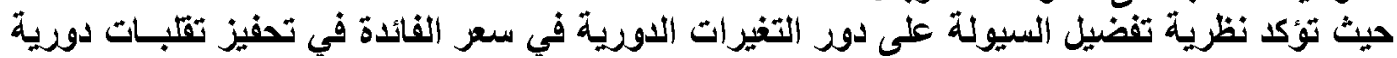

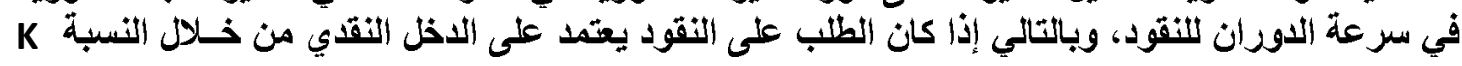

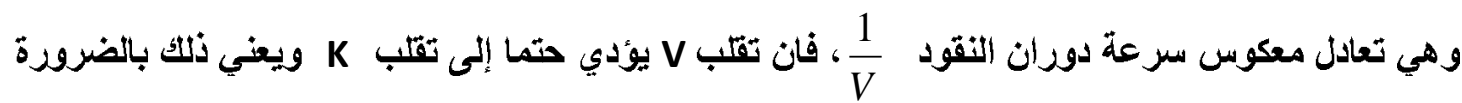

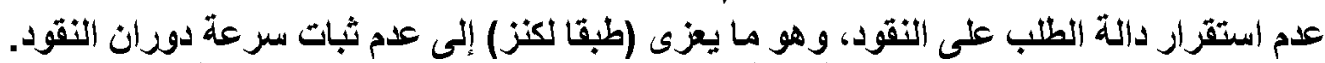

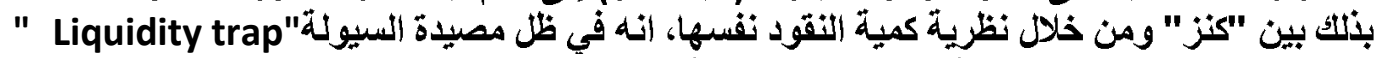

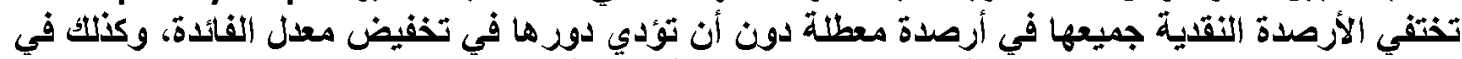

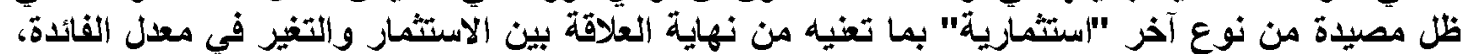

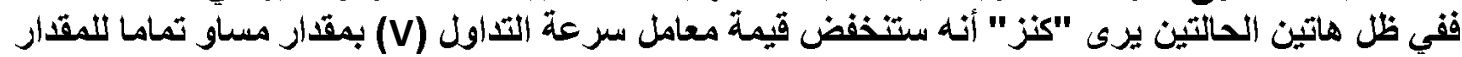

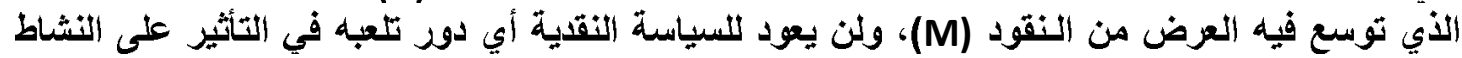

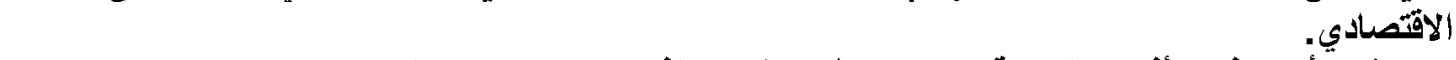

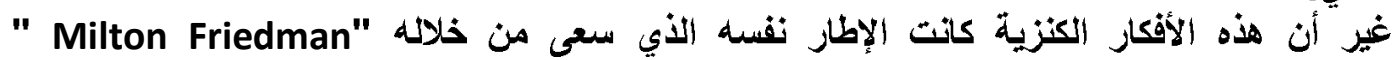

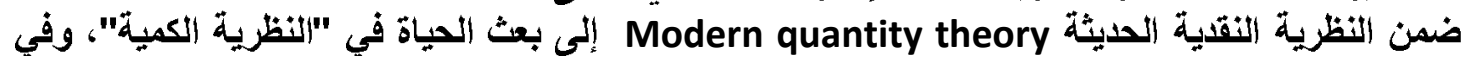

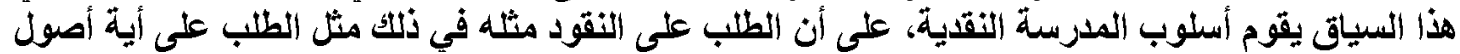

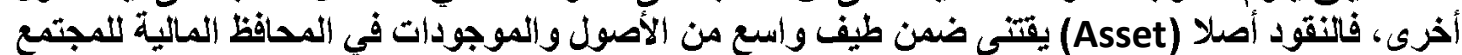
يعود على مالكه بفيض من المنافع والخدمات.

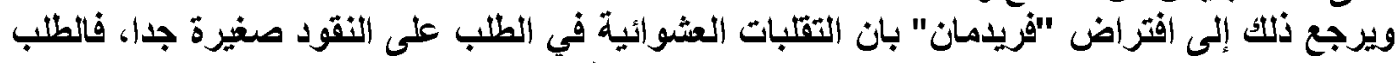

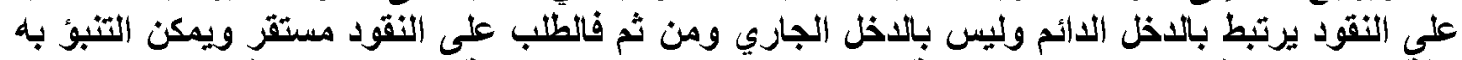

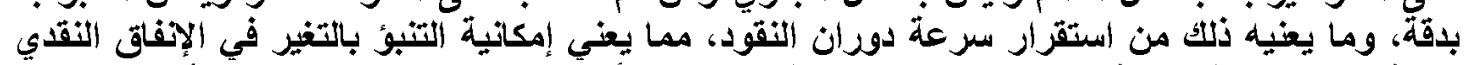

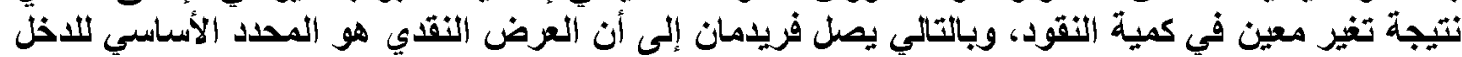

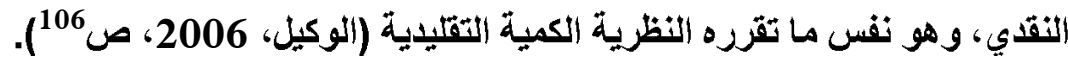


163

.

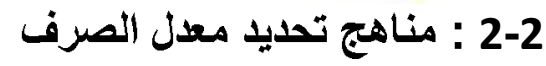

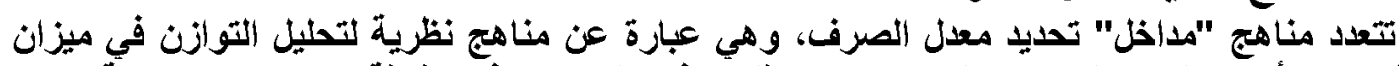

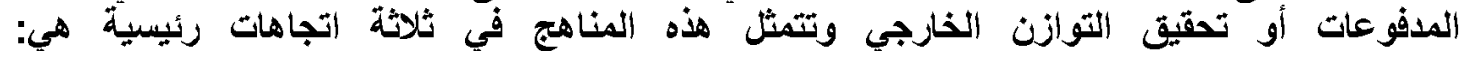

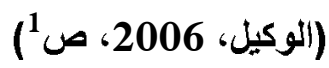

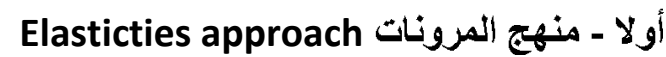

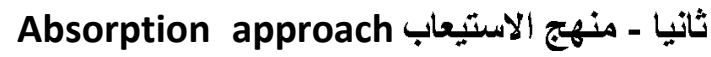

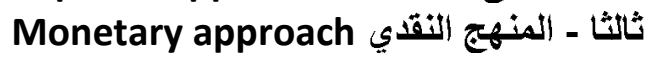

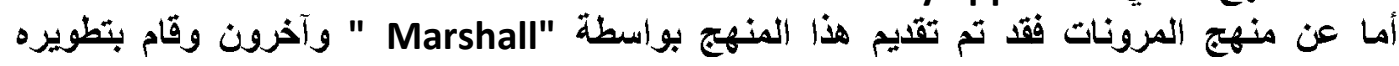
1937- Robinson "

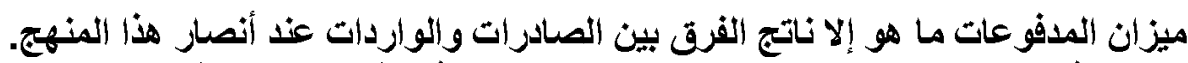

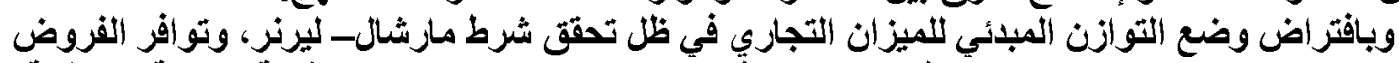

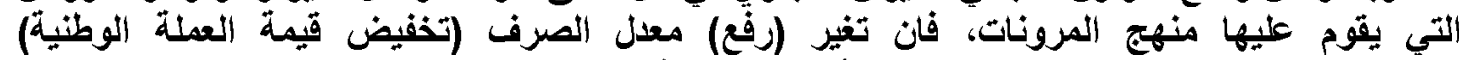

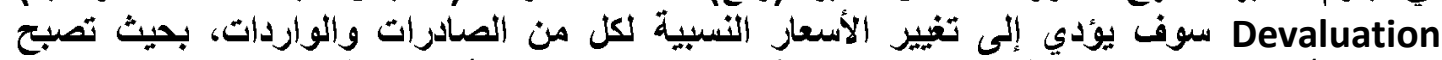

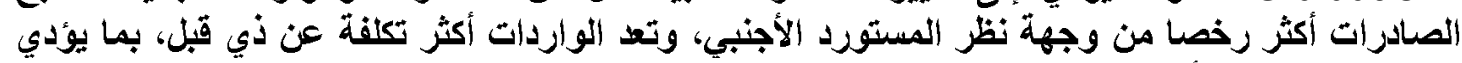

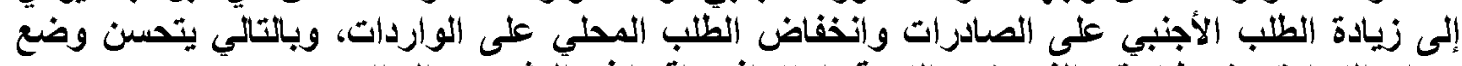

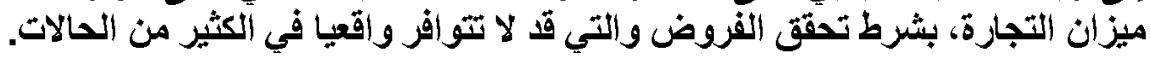

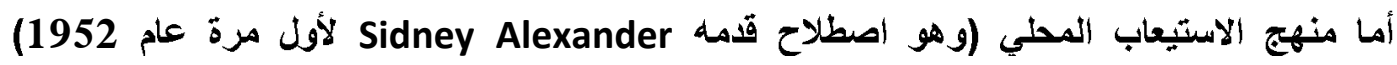

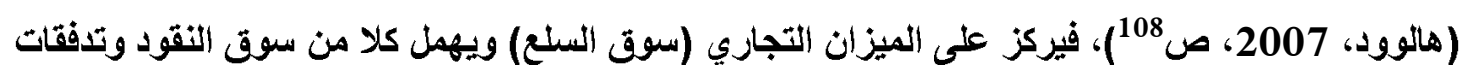

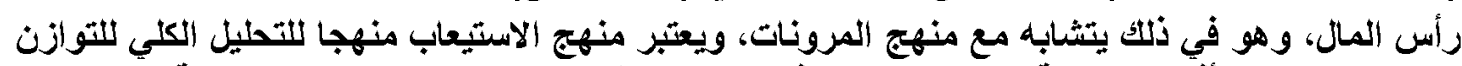

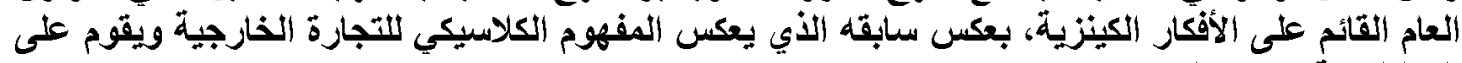
التحليل الاقتصادي الجزئئ الأني.

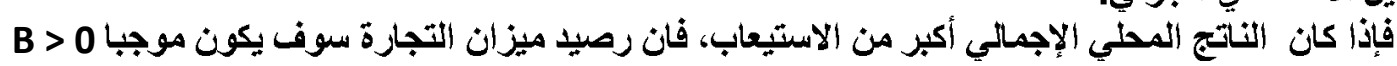

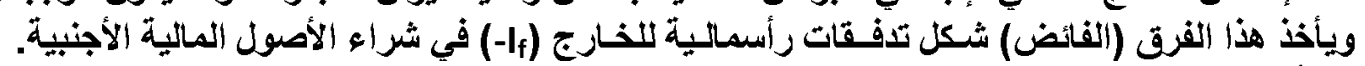

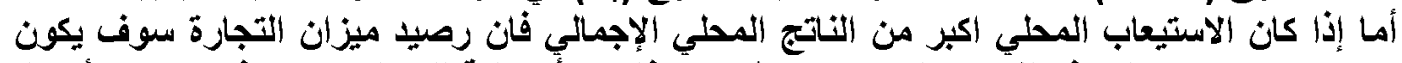

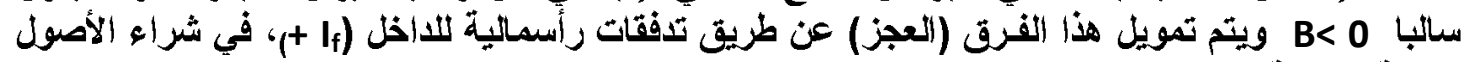
المالية المحية. وإذا كان الناتج المحلي الإجمالي يساوي الاستيعاب المحلي(Y = ( ) )، فان رصيد ميزان التجارة سوف

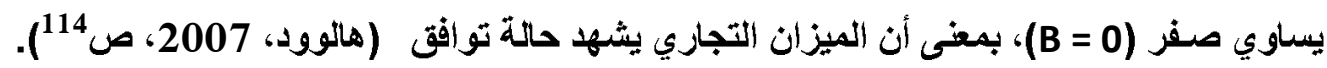

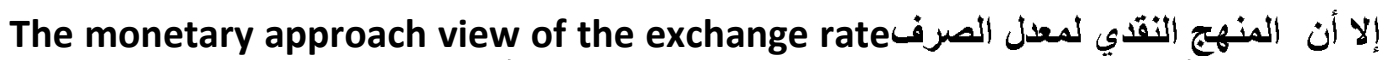

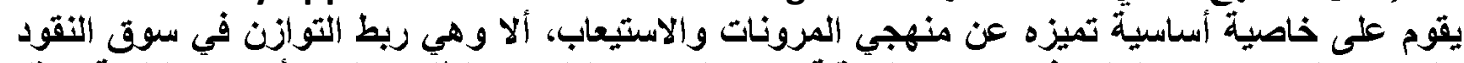

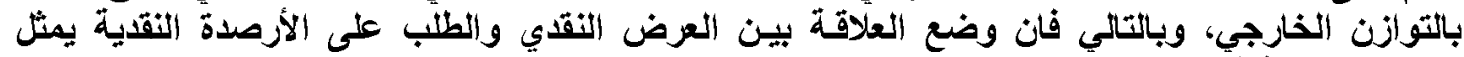

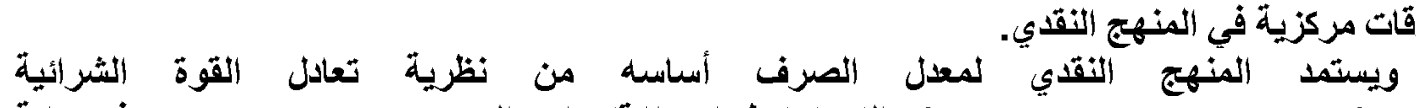
(Purchasing power parity) PPP العشرينات من القرن الماضي (الوكيل، 2006 و ص 
164

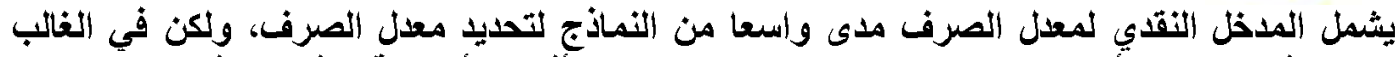

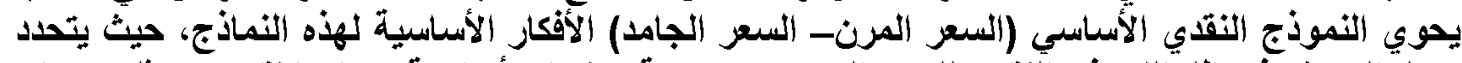

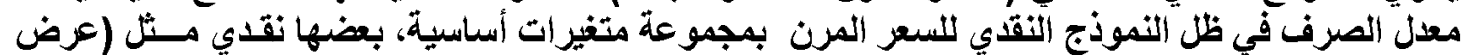

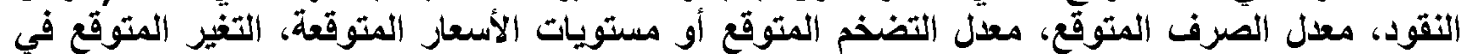

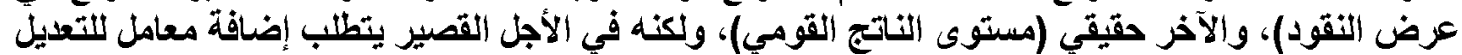

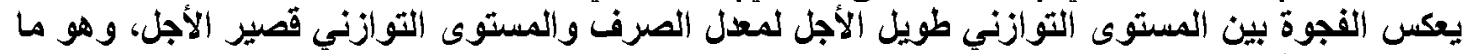

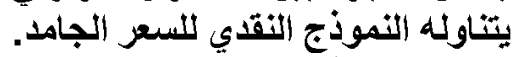

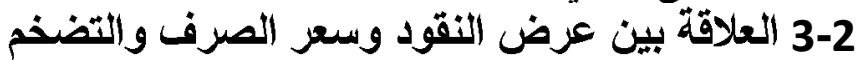

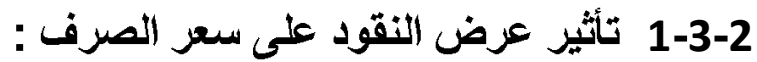
هناك نظريتين لتفسير العلاقة ما بين عزض التوض النقود وسعر الصرف: الأولى في الأجل القصير والثانية في الأجل الطويل. 1-1-3-2 علاقة عرض الأقود وستر الصرف في الأجل القصير:

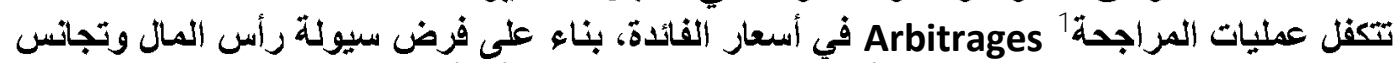

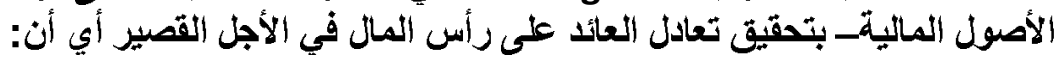
$i=\dot{i}+x$

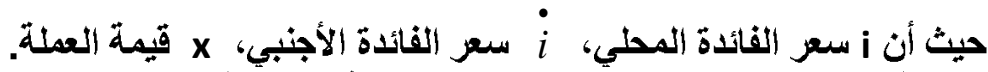

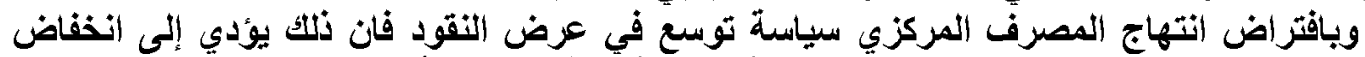

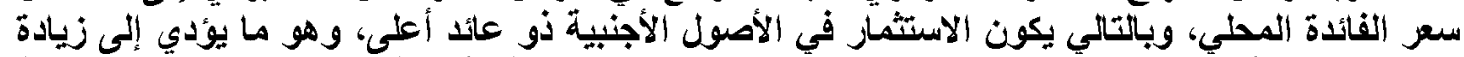

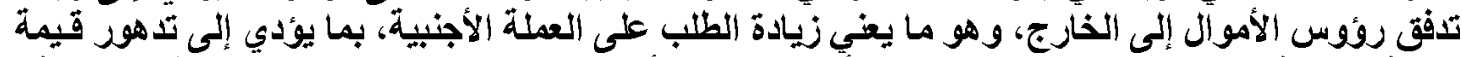

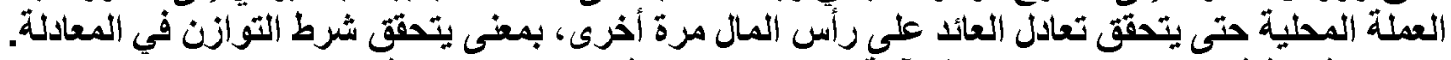

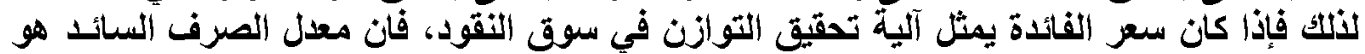

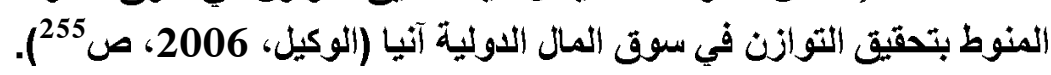

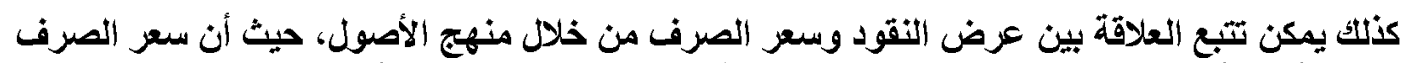

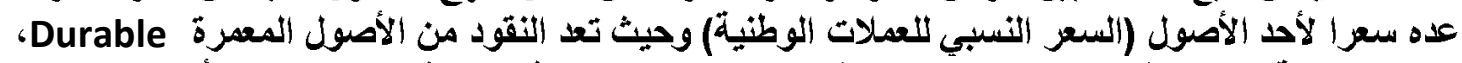

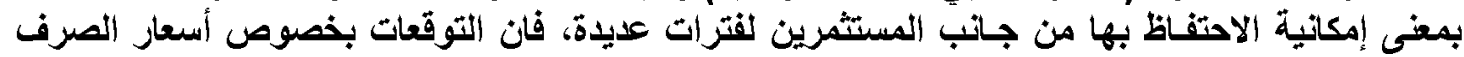

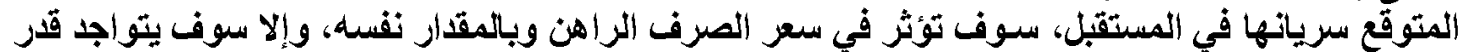

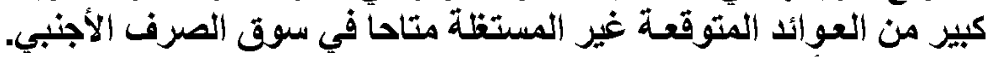

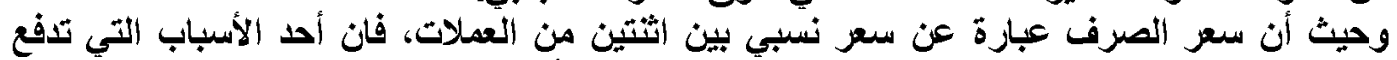

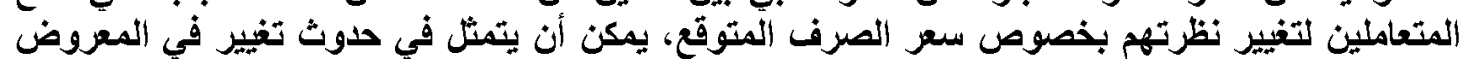

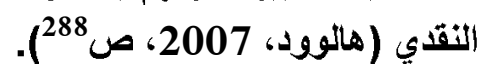

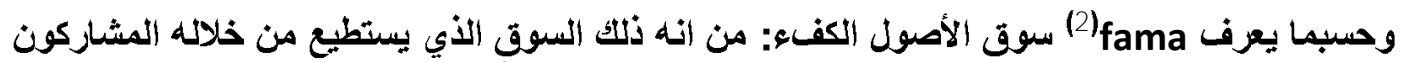

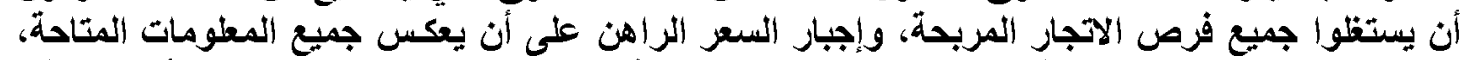

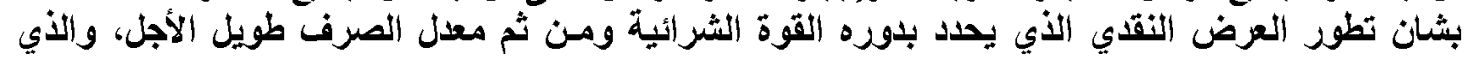

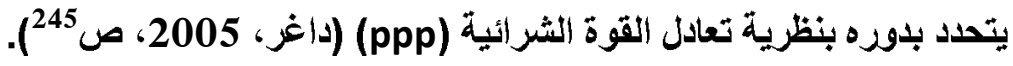

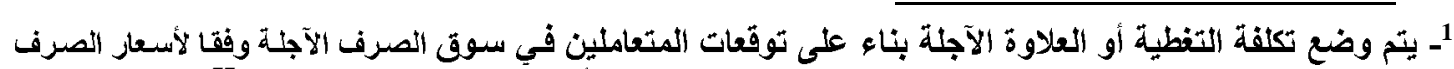

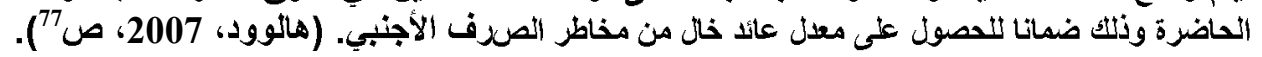

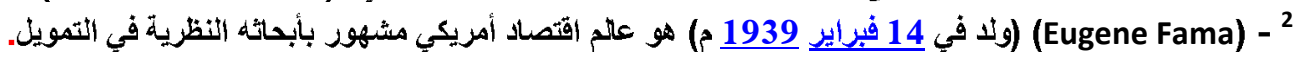




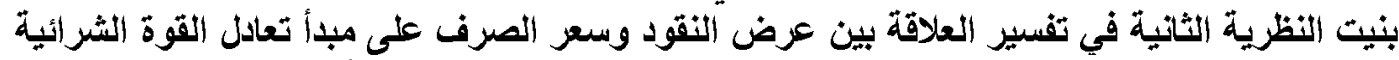

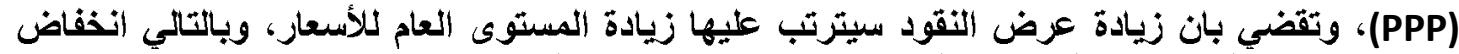

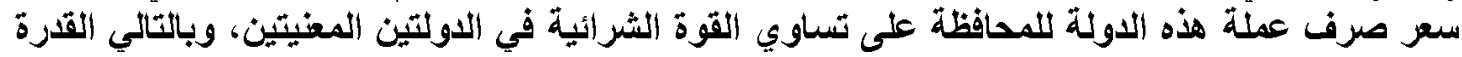

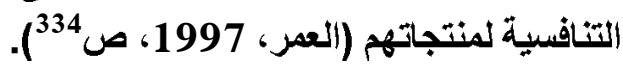

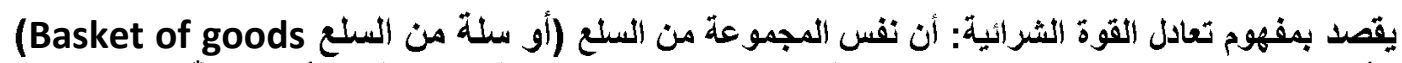

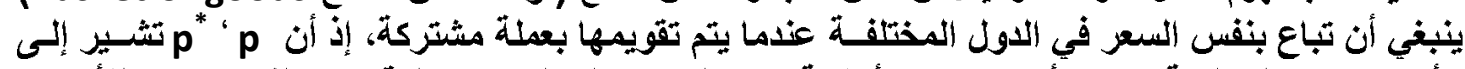

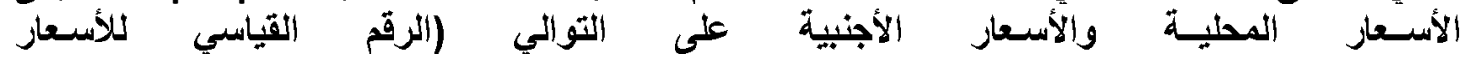

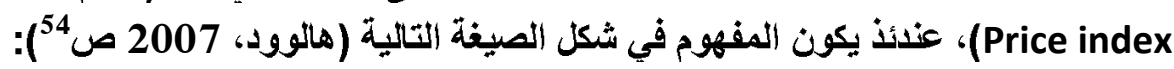
$P=E P^{*}$

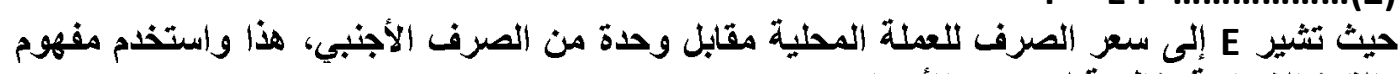

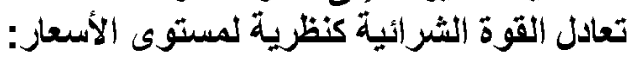

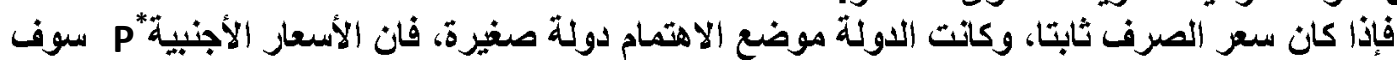
تحدد الأسعار المحلية. بالمقابل استخدم مفهوم تعادل القوة الشرائية كنلف على نطاق واسع كنظرية لسعر الصرف، حيث بإعادة $E=\frac{P}{P^{*}}$ ترتيب المعادلة (2).

لذا يتضح أن نمو مرض النقود يؤدي في الأجل الطويل إلى ارتفاع الأسعار، ويحدد ذلكت مستويات سعر

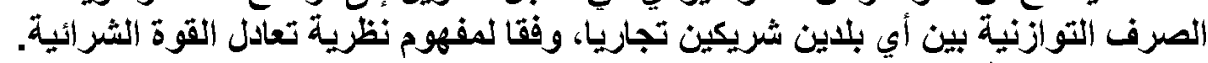

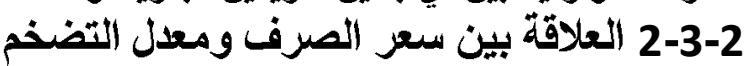

يترتب على تخفيض قيمة العملة ارتفاع في الأسعار المحلية، مما يؤثر على ميزان المقان المدفوعات بطريقة

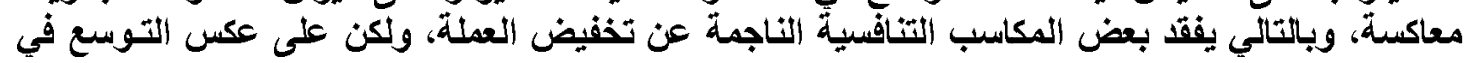

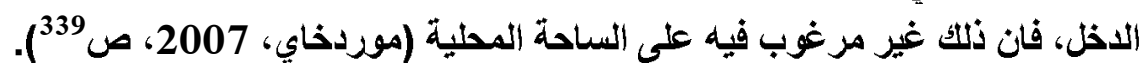

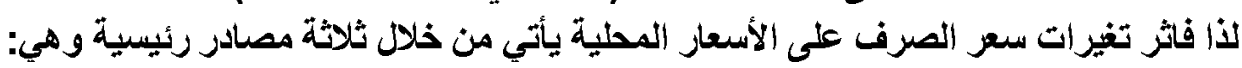
2-1- اثز التغيرات في سعر الصرف على قيمة الواردات من السلع الوسيطة والتهائية. 2-2-2 اثر قيمة الواردات على أسعار السلع الأخرى في الاقتصاد.

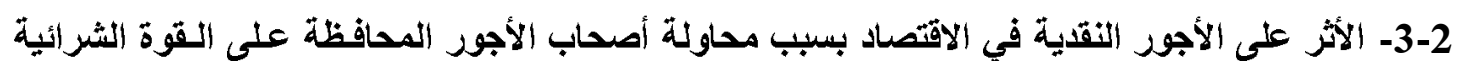

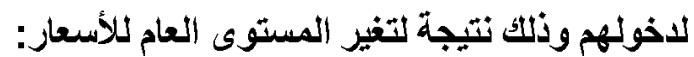

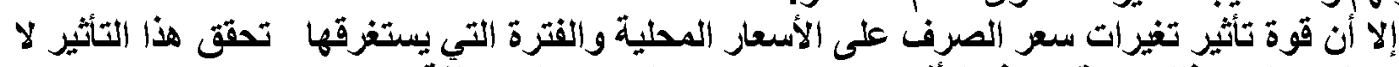

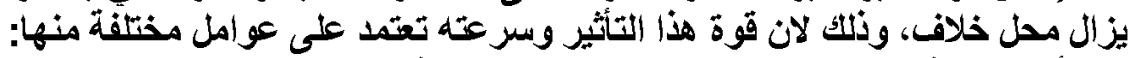

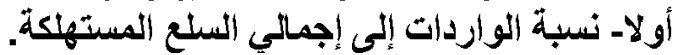

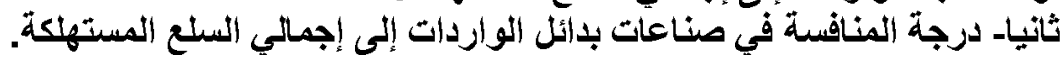

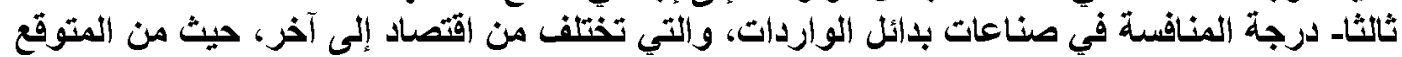

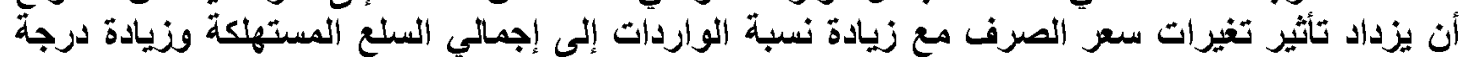

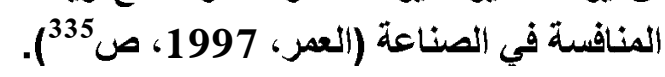

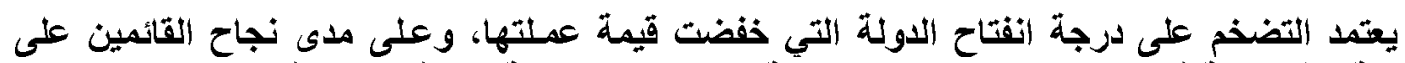

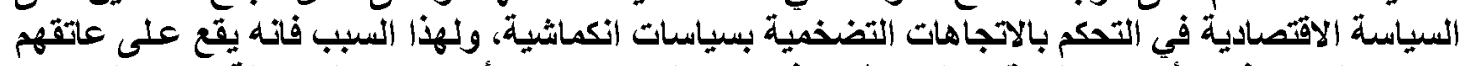

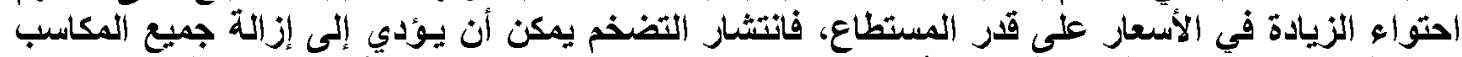

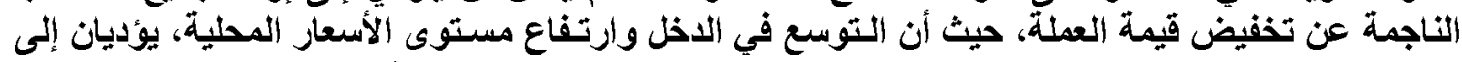

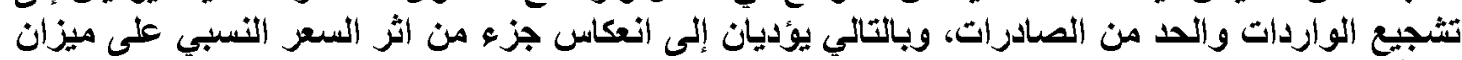

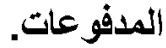


ومن الأهداف المنوطة من وراء إتباع سياسة تخفيض العملة (رفع معدل الصرف الى الى الوحدة الاجنبية)

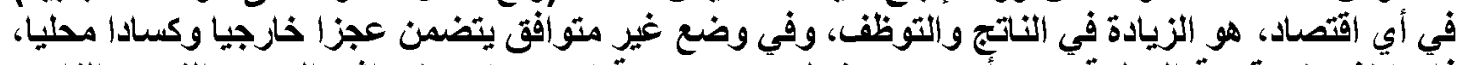

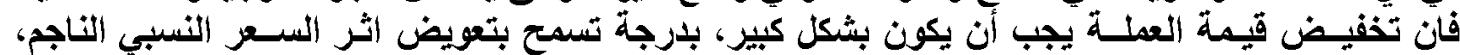

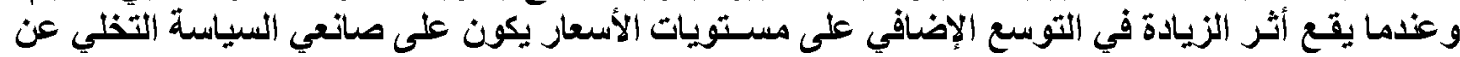

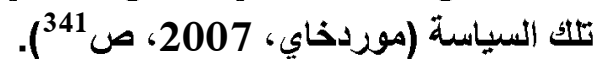

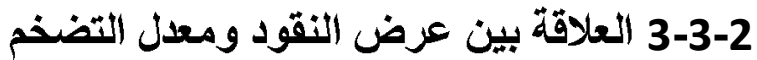

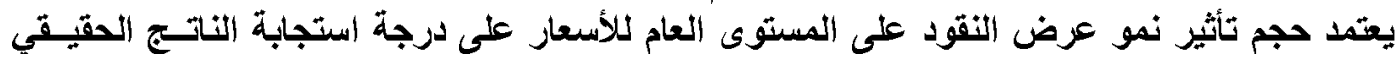

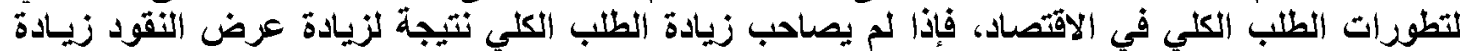

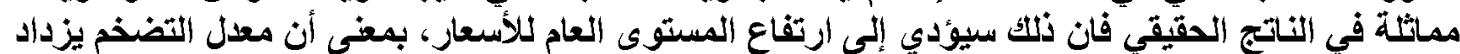

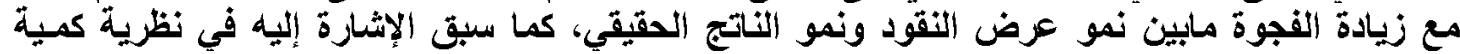

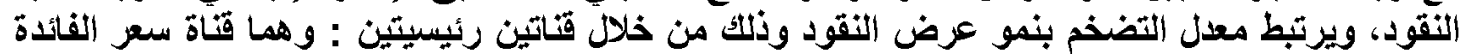

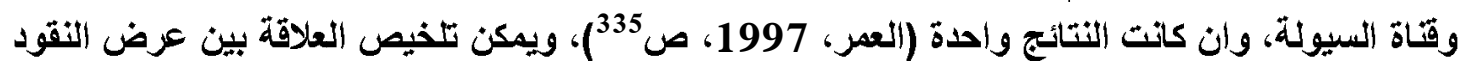
وسعر الصرف ومعـدل التضخم ضمن الشكل (1):

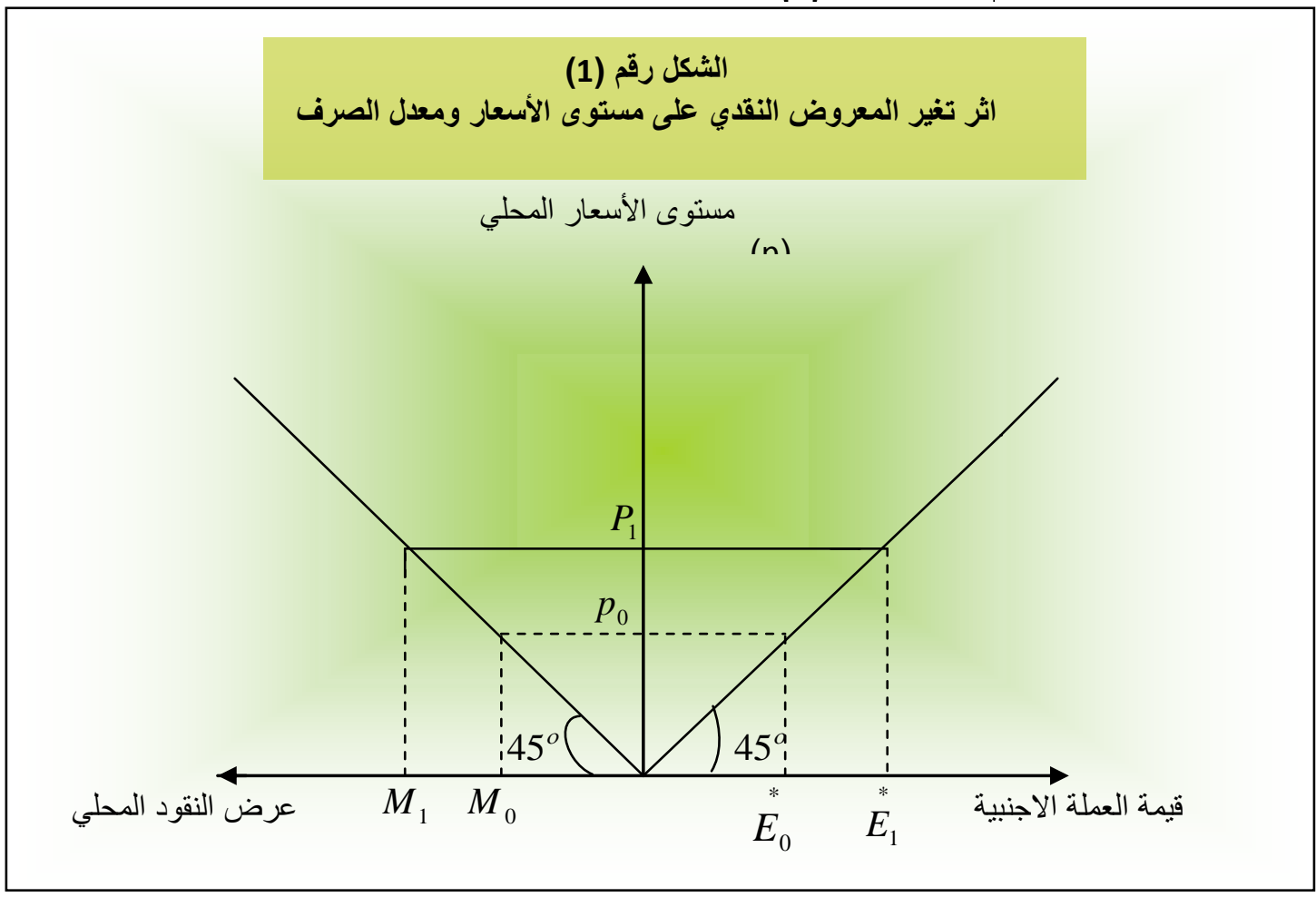

يشير الثكل (1) إلى أن الزيادة النسبية في عرض النقود داخل الاقتصاد المحلي سوف تؤدي إلى زيادة مستوى

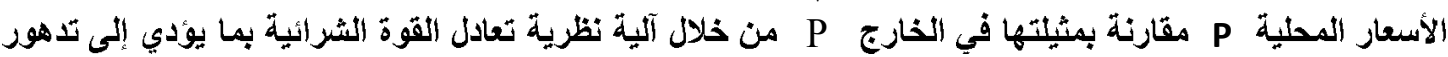

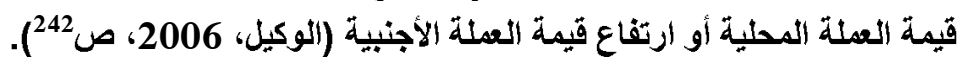


3- سلوك عرض التقود وسعر الصرف والتضخم في الاقتصاد اللبيبي

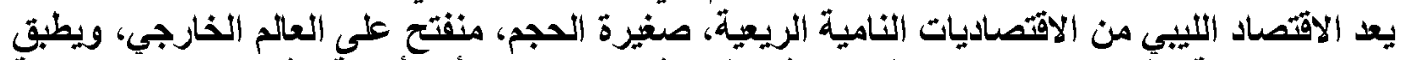

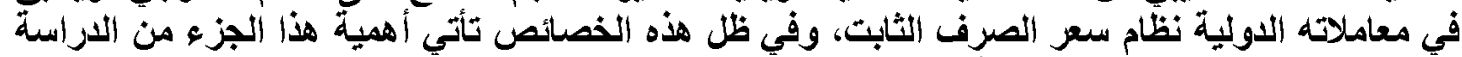

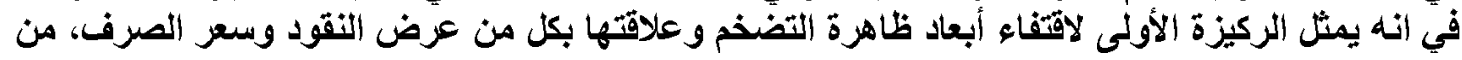

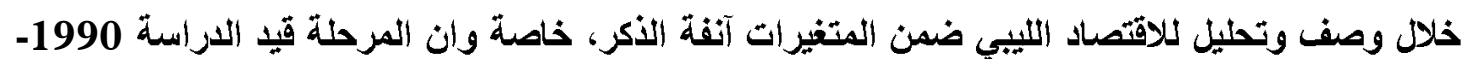
2008 شهدت ظروف متتوعة خلفت أثر ها في هذه المتغيرات.

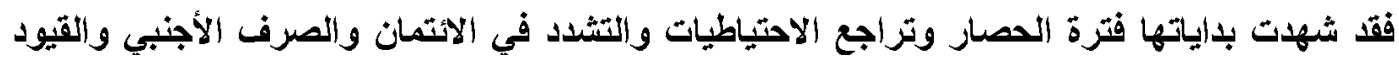

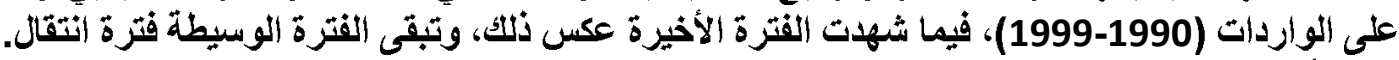

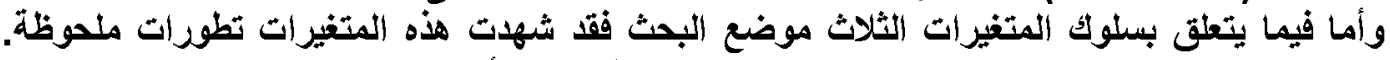

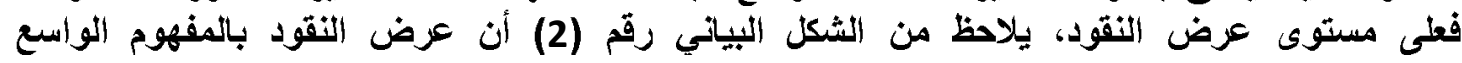

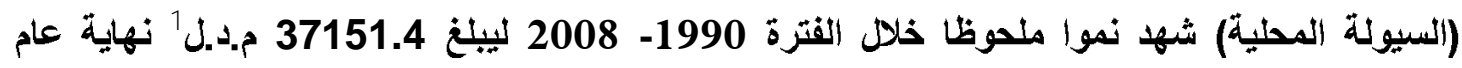
2008 مقابل 6155.3 م.د.ل في نهاية عام 1990، أي بزيادة قدرها 30996.1 م.د.دل، وبمعدل نمو سنوي مركب بلغ 7.4 \% مابل

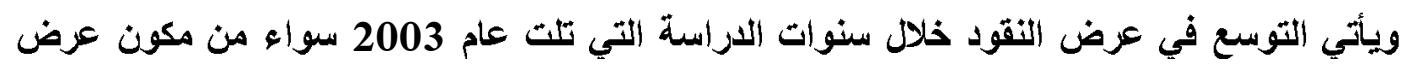

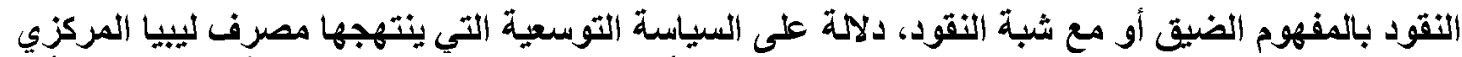

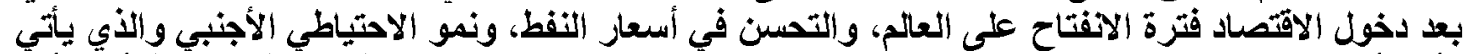

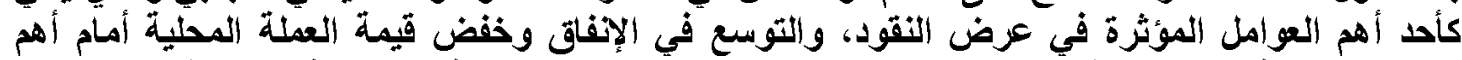

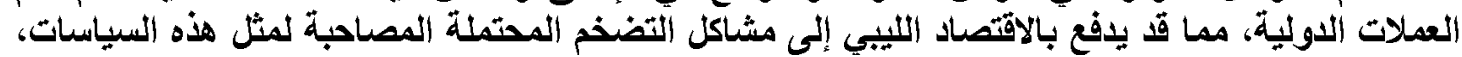

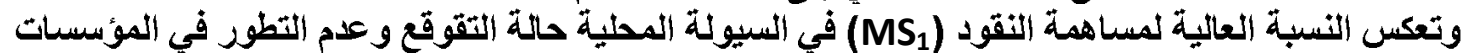

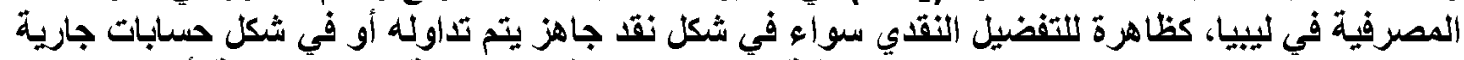

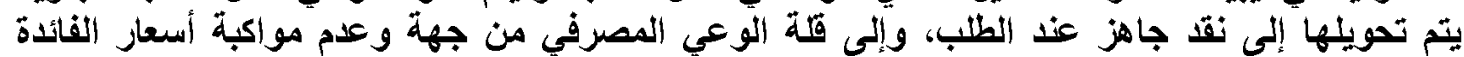

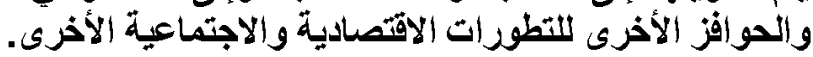




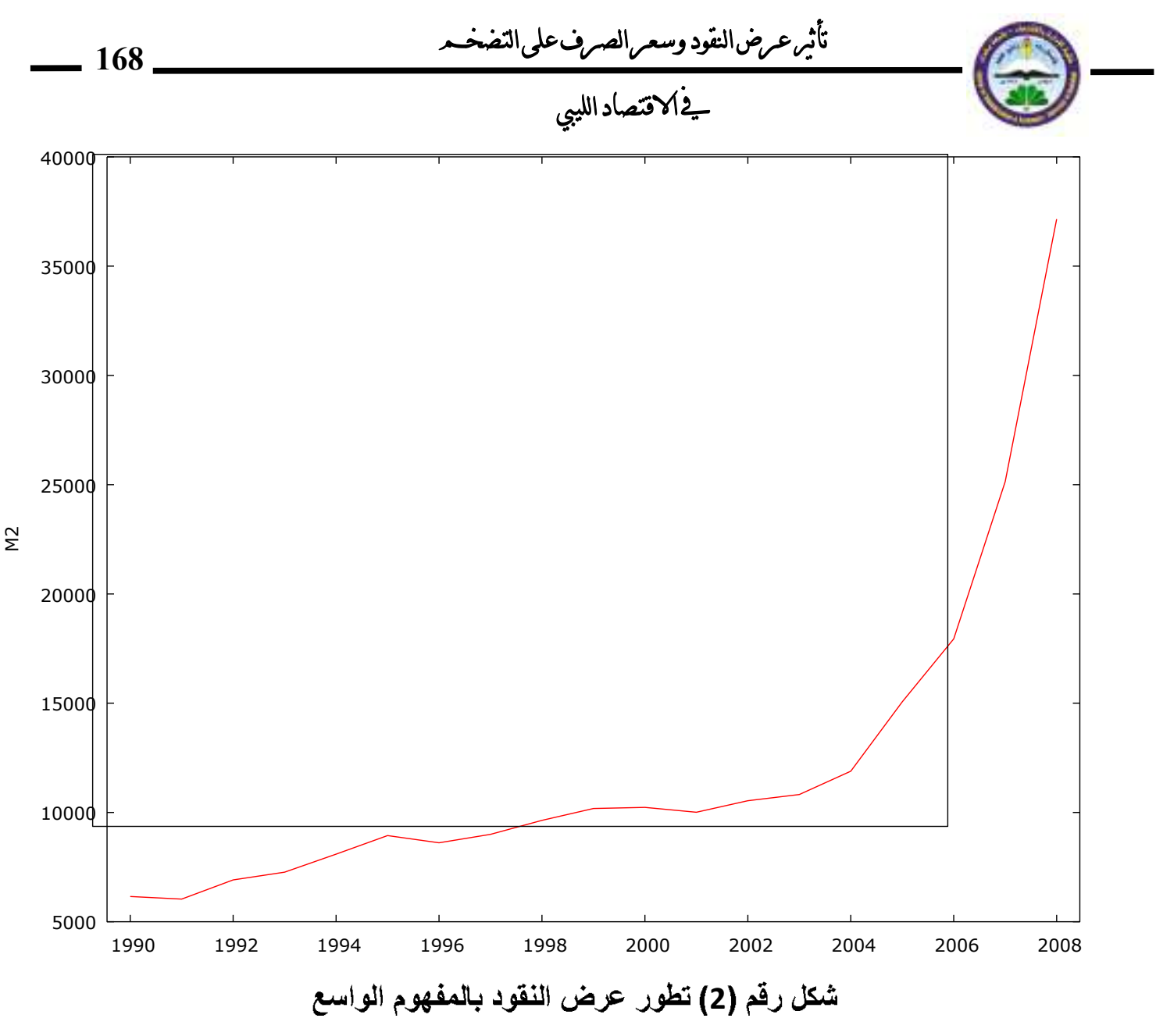

أما بالنسبة لسعر صرف الاينار، وكما يلاحظ من الشكل (3 ) أن سعر صرف الاينار الليبي مقوما

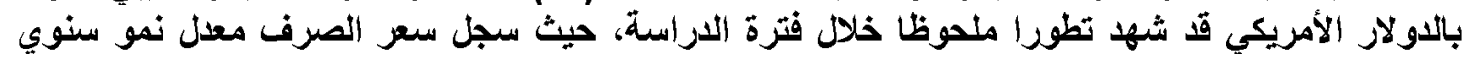

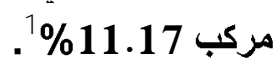

قفيما سجل الدينار الليبي أعلى ارتفاع له أمام الدولار الأمريكي ضمن فترة الدراسة في عام 1990، بلغ

$$
0.2823 \text { من الاينار لكل دولار، يلاحظ انه تراجع في الأعوام التالية حتى العام } 2003 .
$$

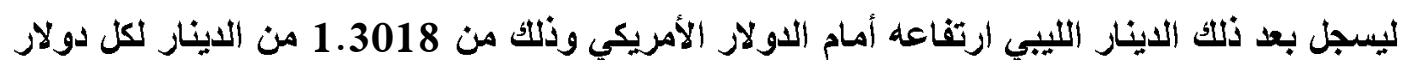

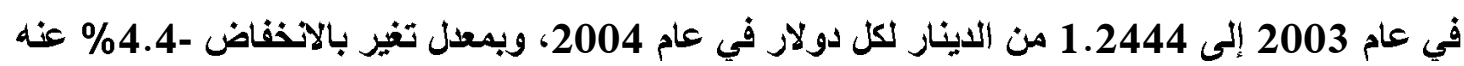
في عام 2003.

وقد سجل 2005 أعلى معدل انخفاض في قيمة الدينار الليبي أمام الدولار الأمريكي، حيث سجل سعر

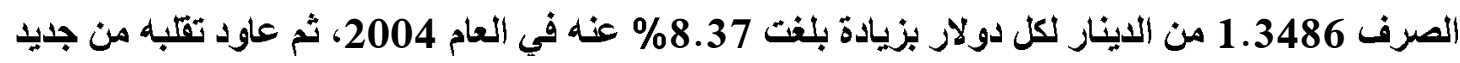
في بقية سنوات الدراسة أمام الدولار. 


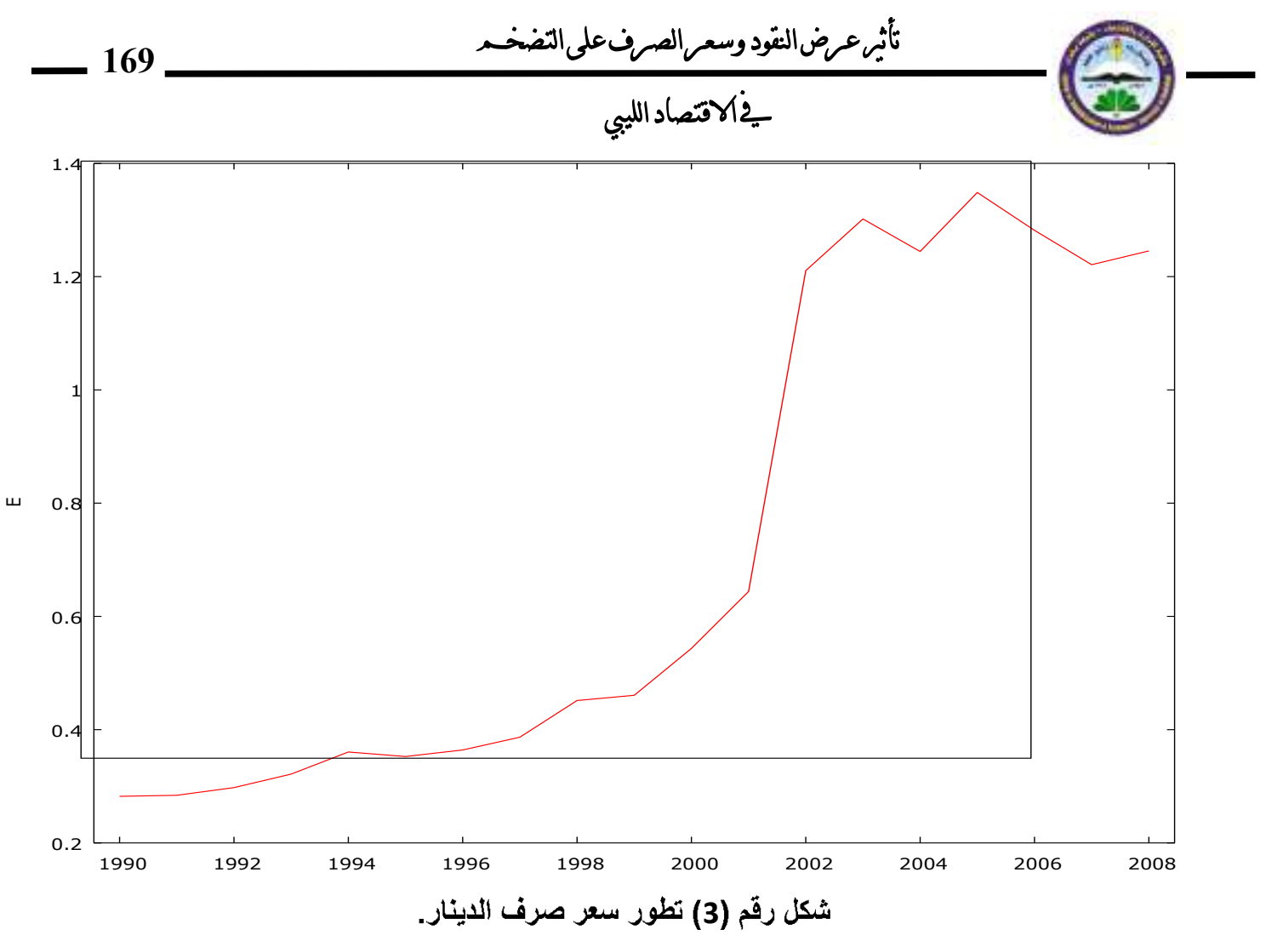

أما عن سلوك التضخم (الرقم القياسي لأسعار المستهلك) فعلى الرغم من التحفظات التي قد يكتنفهات استخدام CPI إلا أنها تظل التعبير الأفضل المتاح عن التثيرات التي طرأت على أسعار السلع والخدمات الضرورية في الاقتصناد الليبي.

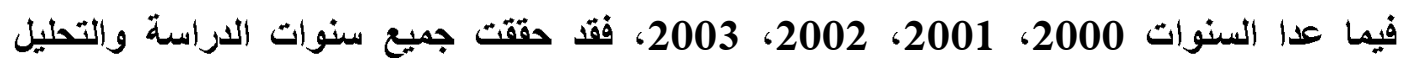
(2008-1990) معلات تغير موجبة، تعكس استمرار تزايد الرقم القياسي للأسعار سنويا، ويالتالى فان فئان

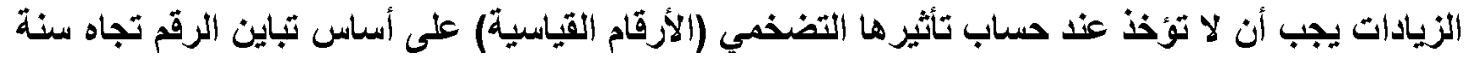

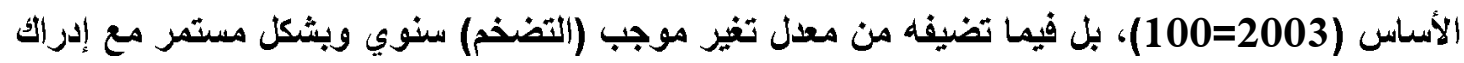
معدل الإضافة التر اكمي. ومن الشكل (4 ) فقد تزايد معدل التضخم السنوي مقاسا بالرقم القياسي لأسعار المستهليك من 10.5\%

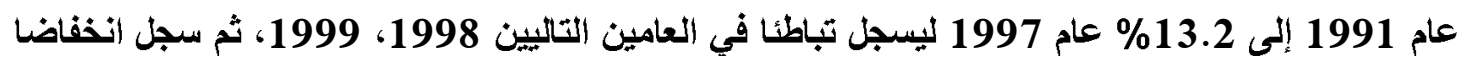
(-2.9، -9.2\%، -9.6، -2.0\%) للأعوام (2000، 2001، 2002، 2003) على التوالبي، ليعاود

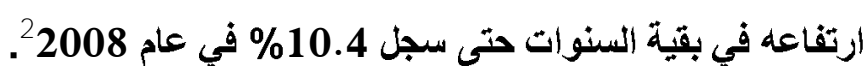

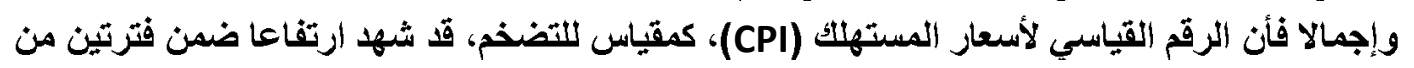

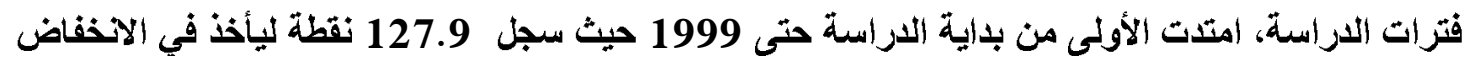
ووصل في 2003 إلى 100 نقطة ثم عاود ارتفاعه ثانية مسجلا في 2008 (123.7) نقطة.

1 ـ تشمل التحفظات من قبيل - النطاق الأي يظطيه CPI فهو يغطي مدينة طرابلس فقط، والاعتماد على أسلوب

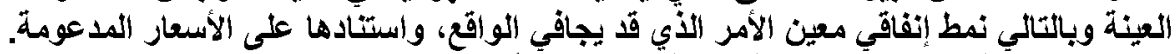

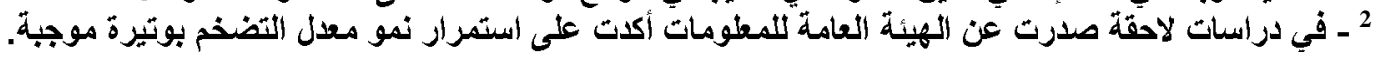




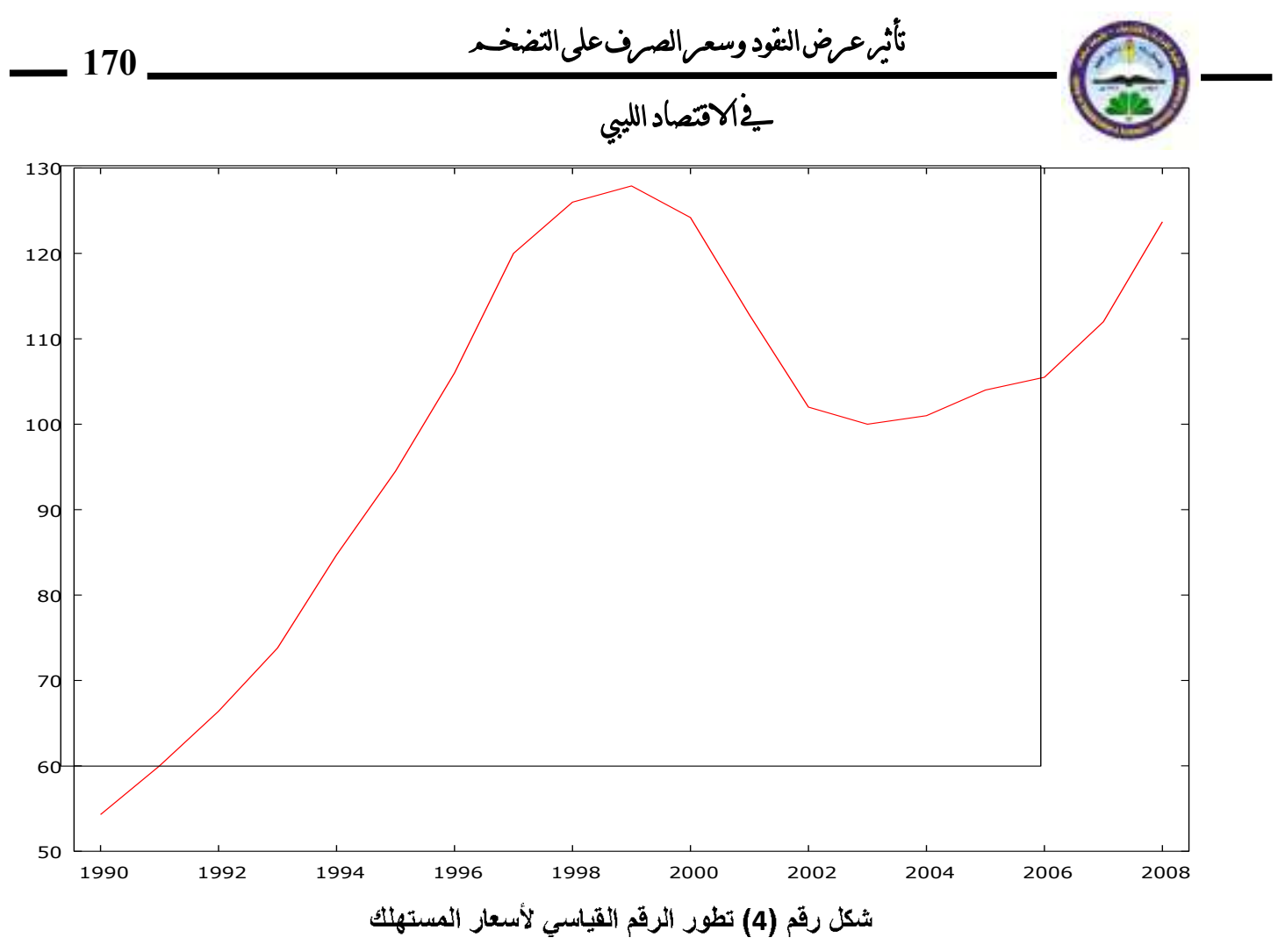

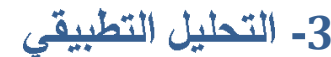
1-4 اختبارات جذر الوحلة (سكون السيلاسل الزّمنية):

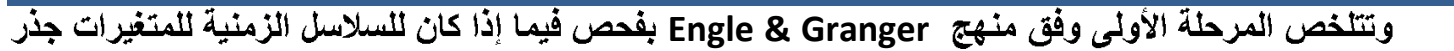

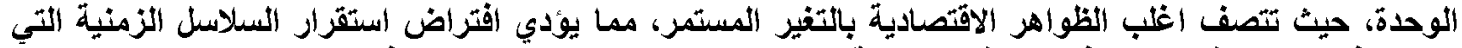

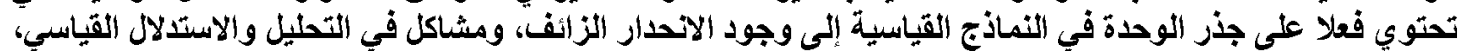

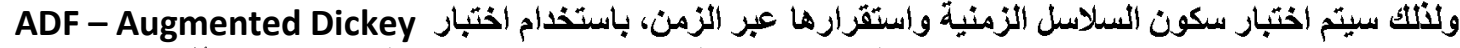

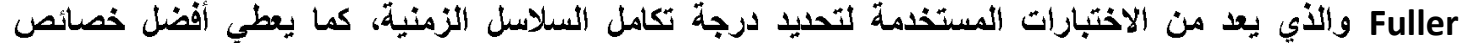

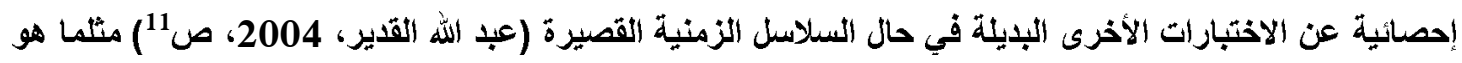
الحال في هذه الاراسة. ولقَّ جرت العادة على إجراء اختبار (ADF) في تقلير النماذج القياسية التالية :

$$
I: \Delta \mathrm{Y}_{t}=\lambda \mathrm{Y}_{t-1}+\Sigma \mathrm{P}_{j} \Delta \mathrm{Y}_{t-j}+\varepsilon_{t}
$$

$$
\begin{array}{r}
I I: \Delta \mathrm{Y}_{t}=\alpha+\lambda \mathrm{Y}_{t-1}+\Sigma \mathrm{P}_{j} \Delta \mathrm{Y}_{t}-j+\varepsilon_{t} \cdot \\
\text { III }: \Delta \mathrm{Y}_{t}=\alpha+\beta \mathrm{T}+\lambda \mathrm{Y}_{t-1}+\Sigma \mathrm{P}_{j} \Delta \mathrm{Y}_{t-j}+\varepsilon_{t}
\end{array}
$$

وللتأكد من وجود جذر الوحدة أو عدمه (أي لتحديد مدى استقرار السلسلة الزمنية) يتم وضع القرضية التالية :

$$
\begin{aligned}
& \text { غير مستقرة.................. } \\
& P=1 \quad \text { or } \quad \lambda=0 \\
& \text { مقابل القرضية التالية: }
\end{aligned}
$$

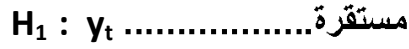

$P<1 \quad$ or $\quad \lambda<0$ 


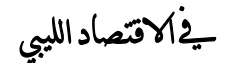

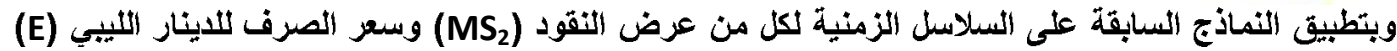

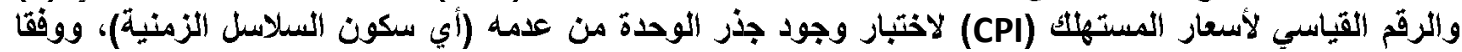

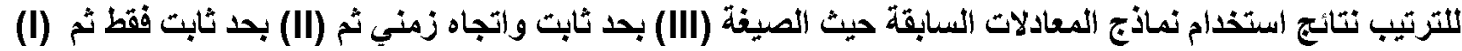

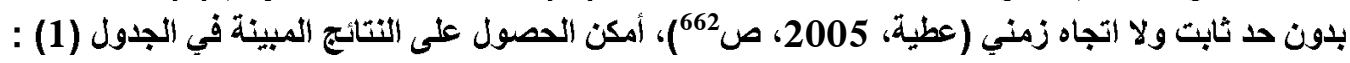

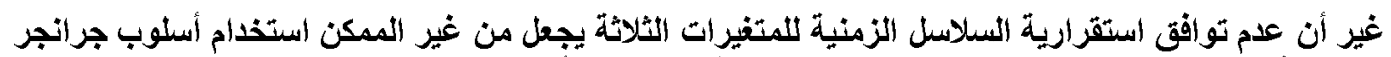

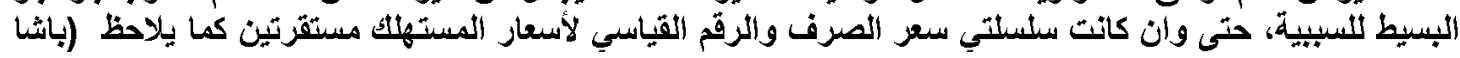

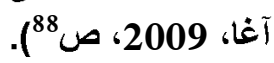

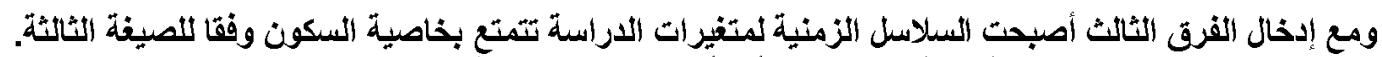

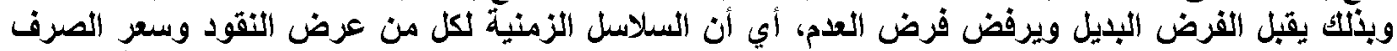

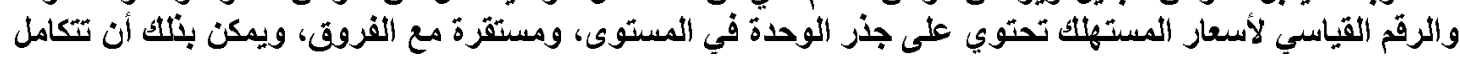
جدول رقم (1) نتائج اختبار الاستقزار

\begin{tabular}{|c|c|c|c|}
\hline III النموذج & النموذج II & النموذج I & ألمتفيز \\
\hline \multicolumn{4}{|c|}{ الاختبار بدون فزوق (في المستوى) } \\
\hline 2.86 & 2.26 & 0.56 & عزض النقود MS ع ع \\
\hline-2.09 & -0.69 & 0.64 & سعر صرف الدينار Eم \\
\hline$-3.69^{\star \star}$ & -2.27 & 0.32 & $\begin{array}{r}\text { المستم الثيكياسي لأسعار } \\
\text { CPI }\end{array}$ \\
\hline \multicolumn{4}{|c|}{ الاختبار بإدراج الفجوة الأولى للفرق الأول } \\
\hline 3.26 & 4.23 & 4.41 & عرض النقود MS2 \\
\hline-2.43 & -2.57 & $-2.20^{\star *}$ & سعر صرف الدينار Eم \\
\hline-1.48 & -1.79 & -1.49 & 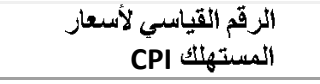 \\
\hline \multicolumn{4}{|c|}{ الاختبار بإدراج الفجوة الأولى للفرق الثانى } \\
\hline-0.41 & 0.64 & 1.07 & عرض النقود MS \\
\hline$-4.25^{\star \star}$ & -4.33 & -4.51 & سعر صرف الدينار Eع \\
\hline-2.11 & -2.03 & $-2.12^{\star \star}$ & الزرقم القياسي لأسعار المستثهيك \\
\hline \multicolumn{4}{|c|}{ الاختبار بإدراج الفجوة الأولى للفرق الثالث } \\
\hline$-5.82^{\star}$ & -3.63 & -3.35 & Mرض النقود MS \\
\hline$-5.4^{*}$ & -5.67 & -5.93 & سعر صرف الأدينار \\
\hline$-3.53^{\star \star *}$ & -3.49 & -3.64 & الثرقتم القياستي لأسعاز \\
\hline-4.38 & -3.75 & -2.50 & \multirow{3}{*}{ الحزجمة } \\
\hline-3.60 & -3.00 & -1.95 & \\
\hline-3.24 & -2.62 & -1.60 & \\
\hline
\end{tabular}

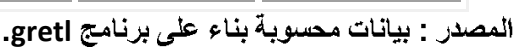

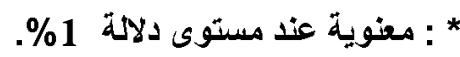

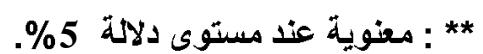

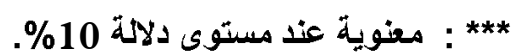


2-4 اختباز التيكامل المشترك ونك

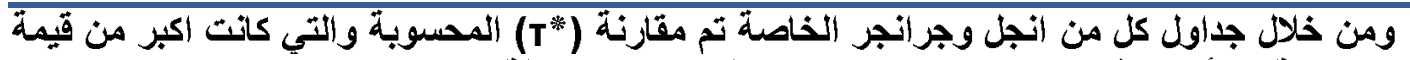

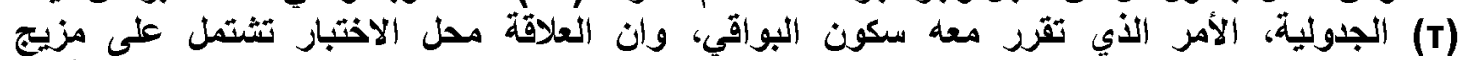
(Combination) (Granger)

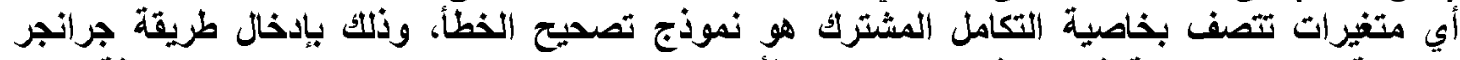

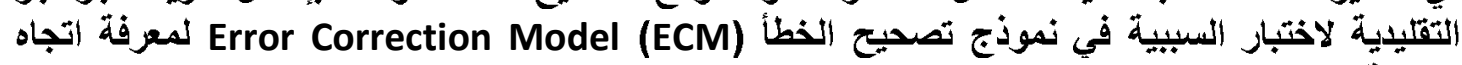

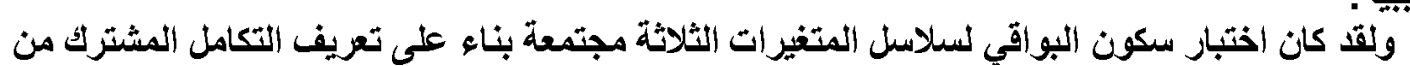
السبيية.

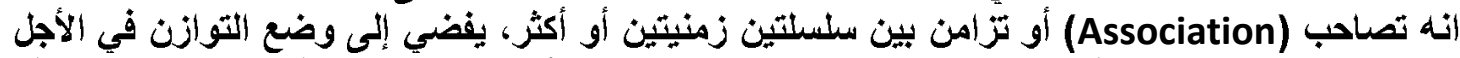

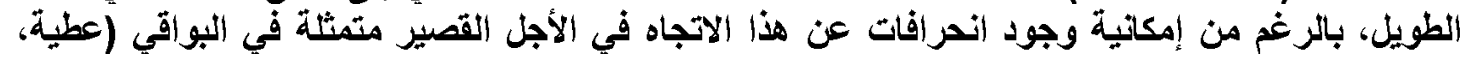

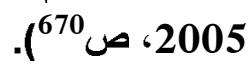

الجدول رقم (2) نتائج اختبار التكامل المشترك

\begin{tabular}{|c|c|c|}
\hline \multicolumn{2}{|c|}{ ADF test } & الاختبار \\
\hline \multicolumn{2}{|c|}{-4.18} & بحد ثابت واتجاه \\
\hline معنوية 10\% (3.84-) & معنوية 5\% (4.16-) & القيمة الحرجة \\
\hline$(C) \sim(0$ & استقرار سلسلة البواقي & القراز \\
\hline
\end{tabular}

المصدر: حسابات الار اسة.

3-4 نموذج تصحيح الخطأ وعلاقة السبيبة لجزانجر

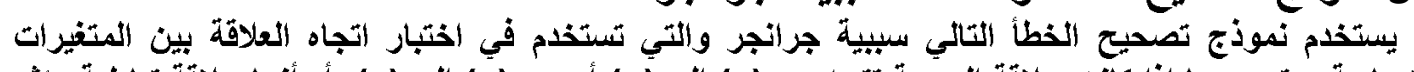

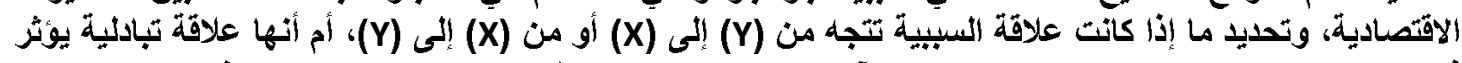

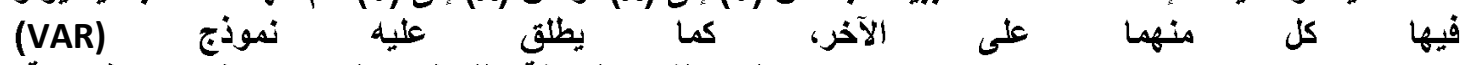
Vector autoregression model

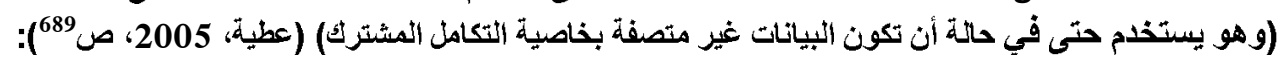
$\Delta C P I_{1 t}=\alpha_{1}+\sum_{i=1}^{m 1} \beta_{1 i} \Delta C P I_{t-i}+\sum_{i=1}^{n 1} \delta_{1 i} \Delta M 2_{t-i}+\theta_{1} \varepsilon_{1 t-7}+Z_{1 t}$

$\Delta M 2_{2 t}=\alpha_{2}+\sum_{i=1}^{m 2} \beta_{2 i} \Delta M 2_{t-i}+\sum_{i=1}^{n 2} \delta_{2 i} \Delta C P I_{t-i}+\theta_{2} \varepsilon_{2 t-4}+Z_{2 t}$

$$
\begin{gathered}
\Delta C P I_{3 t}=\alpha_{3}+\sum_{i=1}^{m 3} \beta_{3 i} \Delta C P I_{t-i}+\sum_{i=1}^{n 3} \delta_{3 i} \Delta E_{t-i}+\theta_{3} \varepsilon_{3 t-1}+Z_{3 t} \\
\Delta E_{4 t}=\alpha_{4}+\sum_{i=1}^{m 4} \beta_{4 i} \Delta E_{t-i}+\sum_{i=1}^{n 4} \delta_{4 i} \Delta C P I_{t-i}+\theta_{4} \varepsilon_{4 t-1}+Z_{4 t} \\
\Delta M 2_{5 t}=\alpha_{5}+\sum_{i=1}^{m 5} \beta_{5 i} \Delta M 2_{t-i}+\sum_{i=1}^{n 5} \delta_{5 i} \Delta E_{t-i}+\theta_{5} \varepsilon_{5 t-2}+Z_{5 t} \\
\Delta E_{6 t}=\alpha_{6}+\sum_{i=1}^{m 6} \beta_{6 i} \Delta E_{t-i}+\sum_{i=1}^{n 6} \delta_{6 i} \Delta M_{2 t-i}+\theta_{6} \varepsilon_{6 t-1}+Z_{6 t}
\end{gathered}
$$




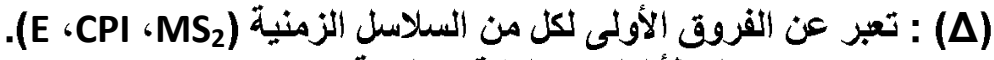

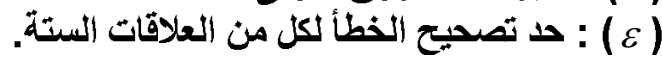

) : n6،m6،n5،m5،n4،m4،n3،m3،n2،m2،n1، (m1 باستخدام أسلوب معيار الحد الأدنى لخطا التتبؤ النهائي (FPE) وفقا للصيغة:

$$
F P E_{m}=\left(\frac{T+K}{T-K}\right)\left(\frac{S S R_{m}}{T}\right)
$$

حيث : Akiak's Final Prediction Erro = FPE معيار الحد الأدنى لخطأ التثبؤ النهائي.

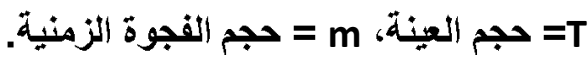

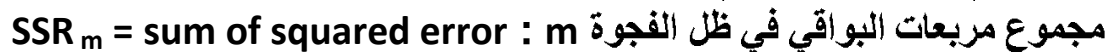

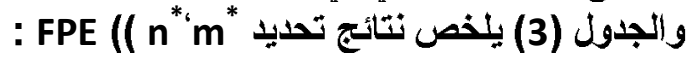

جدول رقم (3) نتائج اختبار السبيية

\begin{tabular}{|c|c|c|c|c|}
\hline \multirow[b]{2}{*}{ 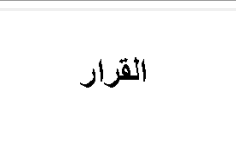 } & \multirow[b]{2}{*}{ تنيجة المقارنة لـ FPE } & \multicolumn{2}{|c|}{ علاقة الاتعدار } & \multirow[b]{2}{*}{ رقم المعادلة } \\
\hline & & 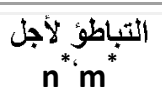 & 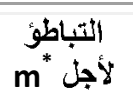 & \\
\hline CPI تسبب MS & $m_{1}^{*}(39.0)<m_{1}^{*} \cdot n_{1}^{*}(18.0)$ & 1 & 1 & (7) \\
\hline MS تسبب ل لابل & $\left.\left.m_{2}^{*}(643196.1) 1728179.5\right)>m_{2,}^{*} n_{2}^{*}\right)$ & 1 & 1 & (8) \\
\hline CPI تسبب E & $m_{3}^{*}\left(49.1</ m_{3 .}^{*} n_{3}^{*}(13.7)\right.$ & 4 & 1 & (9) \\
\hline تسبب CPI & $\mathrm{m}_{4}^{*}\left(0.022<\left(\mathrm{m}_{4,}^{*} \mathrm{n}_{4}^{*}(0.011)\right.\right.$ & 1 & 1 & (10) \\
\hline MS & $\mathrm{m}_{5}^{*}(1664936.7) 1715523.8\left(>\mathrm{m}_{5}^{*}{ }^{\circ} \mathrm{n}_{5}^{*}\right)$ & 1 & 1 & (11) \\
\hline Eسبب $M S_{2}$ & $m_{6}^{*}\left(0.024</ m_{6 .}^{*} n_{6}^{*}(0.021)\right.$ & 1 & 1 & (12) \\
\hline
\end{tabular}

الهصدر: حسابات الدراسة

ويهذا يمكن القول: أن زيادة حجم الكتة النقاية أو السيولة المحلية (عرض النقود سعر صرف الدينار الليبي E خلال فترة الاراسة (1990-2008)، قد ساهمت في تأجيج الأسعار المحلية وكانت مسئولة في جزء مهم عن التضخم المحلي وفقا لمقياس الرقم القياسي لأسعار المستهلك في الاقتصاد فئس الليبي للفترة ذاتهاً ووفي جزا للنتيجة السابقة. 


\section{استنتاجات الدراسة الداسة}

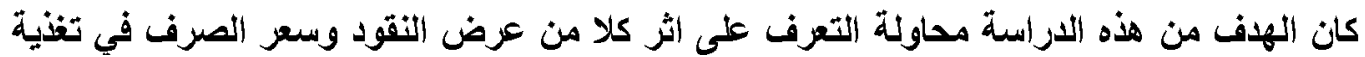

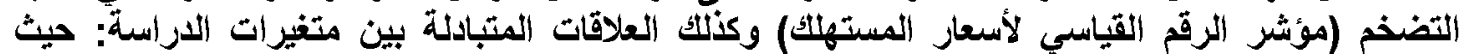

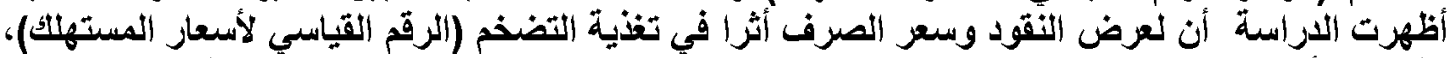

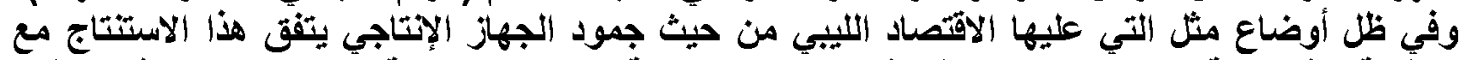

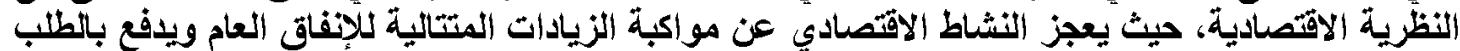

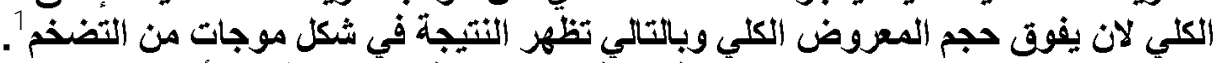

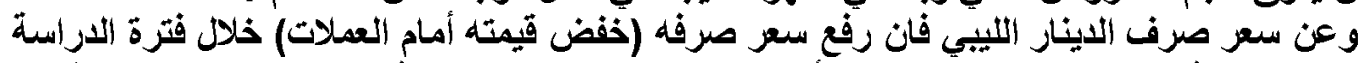

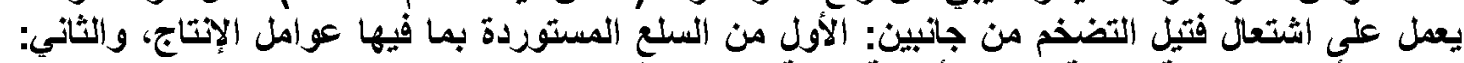

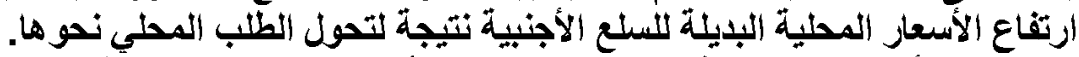

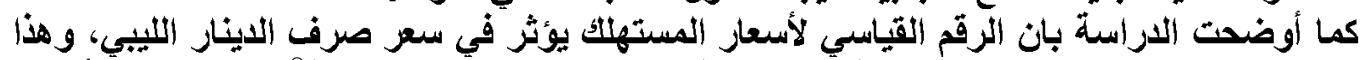

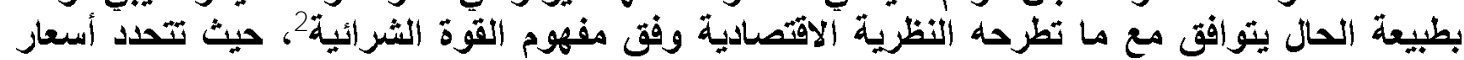

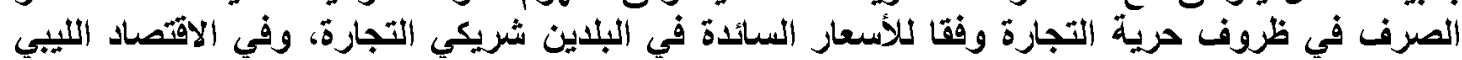

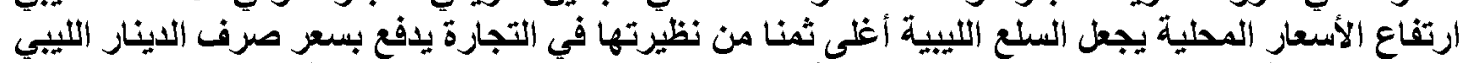

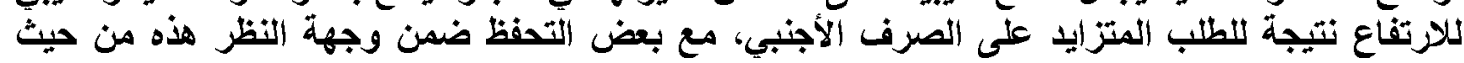

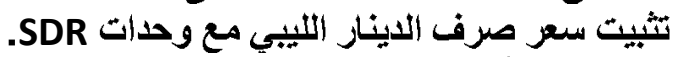

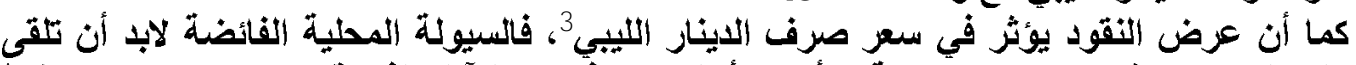

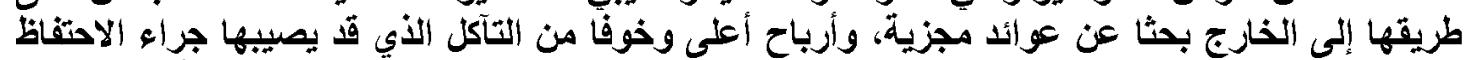

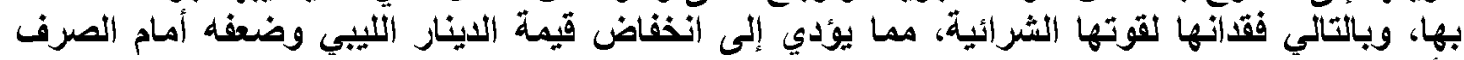

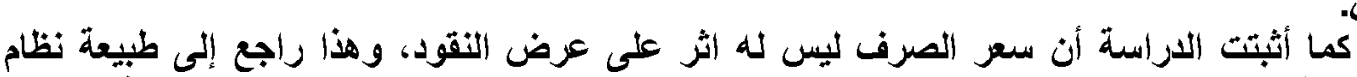
الأجنبي.

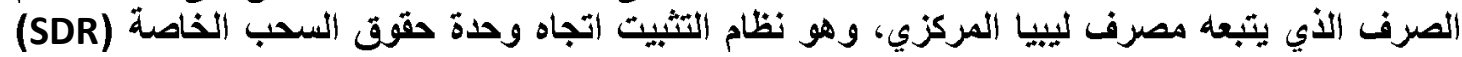

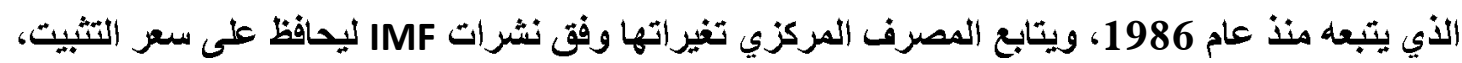

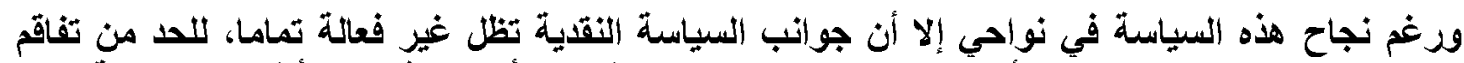

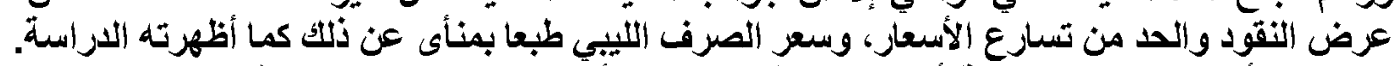

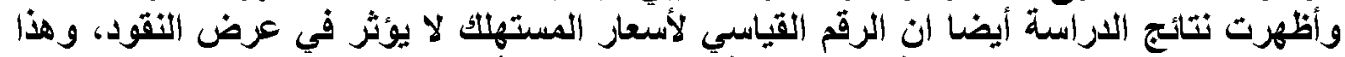

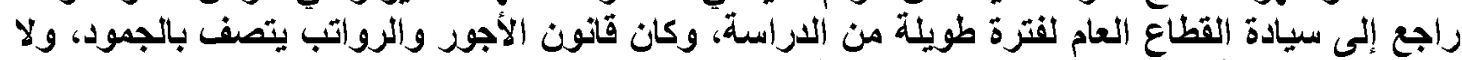

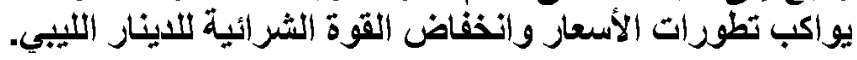

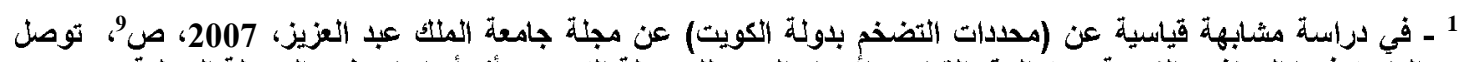

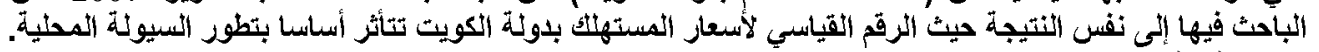

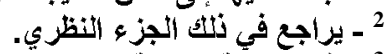

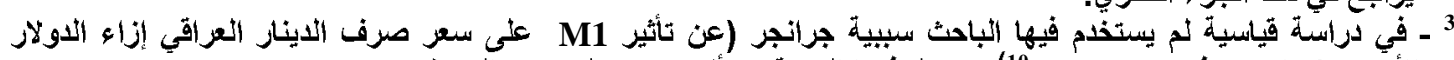

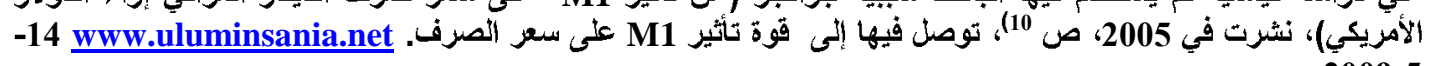




\section{توصيات الدراسة}

1- ضرورة تفعيل مصرف ليبيا المركزي لأدواته المباشرة وغير المباشرة، وان كاتت الأدوات المباشرة

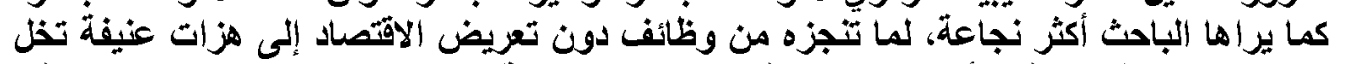

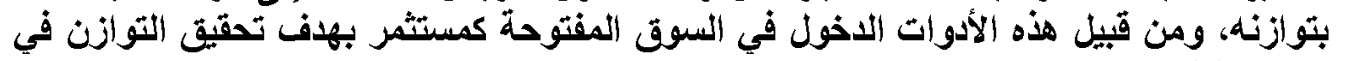

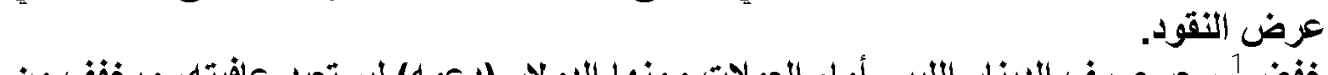

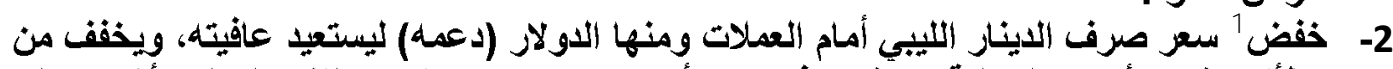

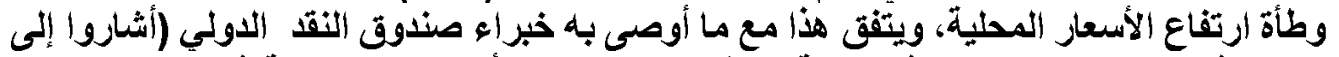

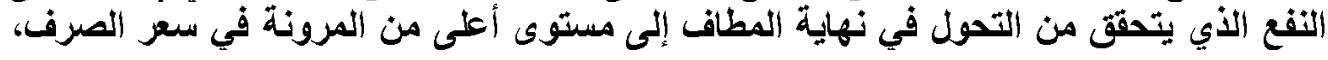

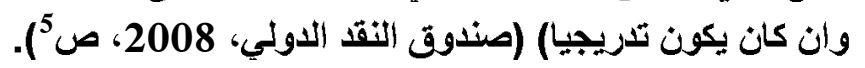

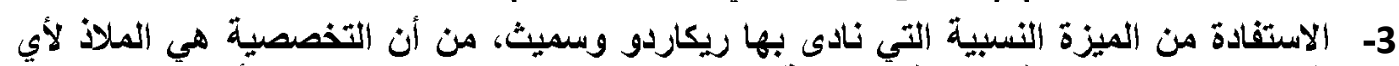

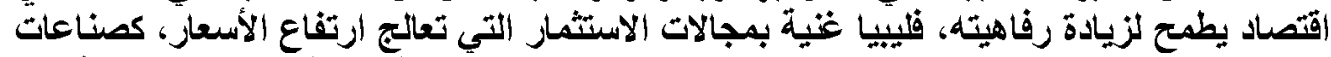

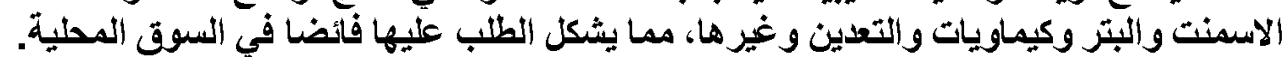

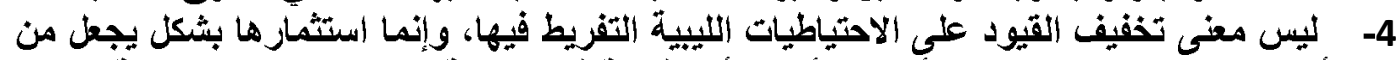

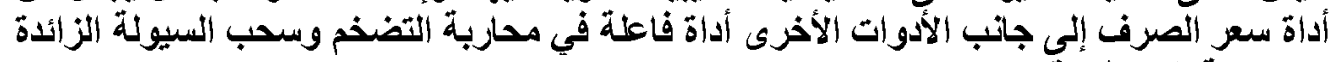
عن حاجة النشاط الإثتصادي.

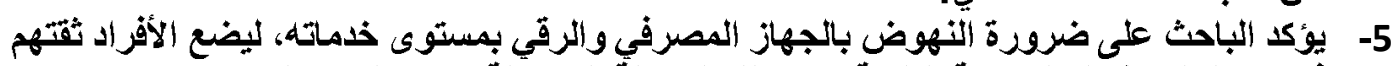

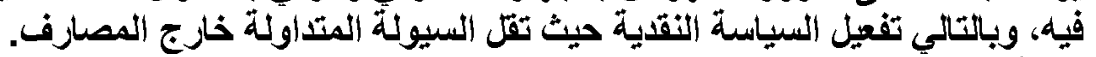

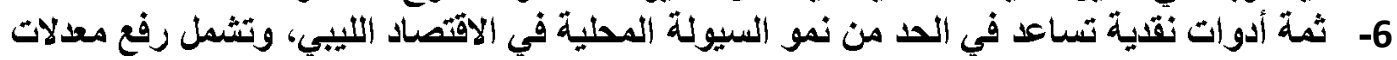

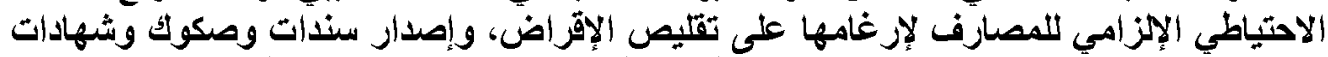

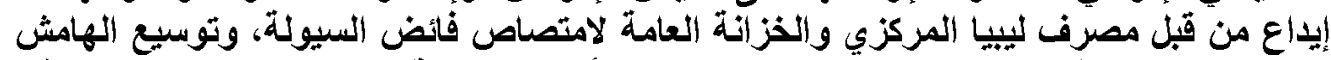

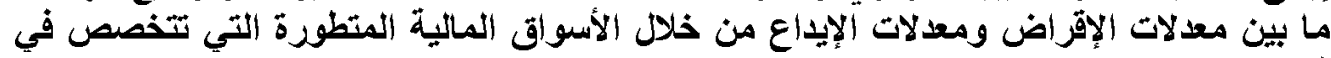


176

1- الوكيل، نشأت محمد. "التوازن النقدي ومعدل الصرف دراسة تحليلية مقارنة". شركة ماس،

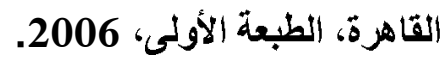

2- هالوود، سي بول، وماكدونالد، رونالد، ترجمة محمود حسن حسني، "النقود والتمويل الدولي. دار المريخ، الرياض، الطبعة بلا، 2007.

3- براين، هيللر، ترجمة فتحي أبو سدرة وآخرون، "الاقتصاد التحليلي الكلي نماذج ومناظرات

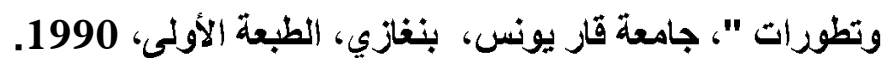

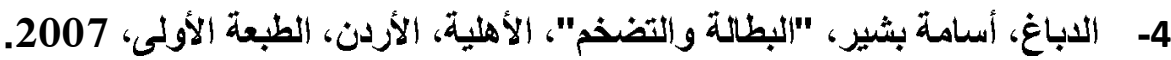
5- داغز، محمود محمد، "الأسواق المالية"، الثروق، عمان، الطبعة الأولى، 2005.

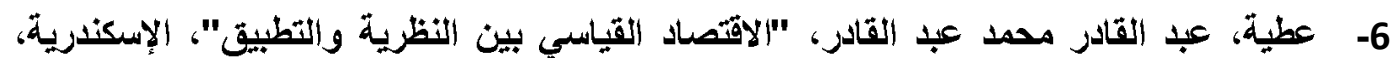
الطبعة بلا، 2005.

7- كرياتين، موردخاي، ترجمة محمد ابراهيم منصور، الاقتصاد الدولي مدخل السياسات، 2007. ثانيا_ المجلات والاوريات

1- داغر، محمود محمد. "لاتجاهات الحديثة في تحليل دالة عرض النقود"، مجلة جامعة الملك عبد الززيز، 1988

2- العمر، حسين، "محددات التضخم بدولة الكويت"، مجلة جامعة الملث عبد العزيز، 2007. www.ksu.edu.sa 3- العمر، حسين، "تأثير عرض النقا وسعر الصرف على التضخم في الاقتصاد الكويتي"، مجلة

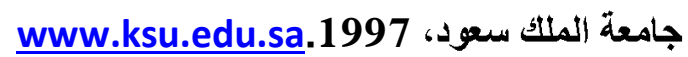
4- بخيث، حيدر نعدة، "تأثير عرض النقل (M1) على سعر الصرف التوازني للاينار العراقي"،

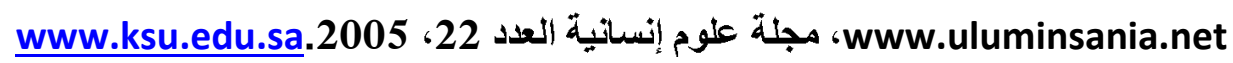

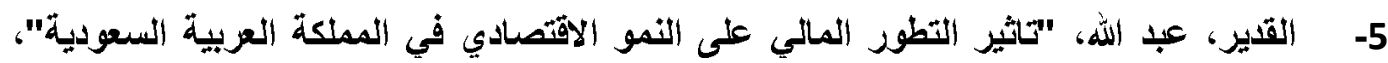
مجلة جامعة الملتك سعود، الرياض، 2004.

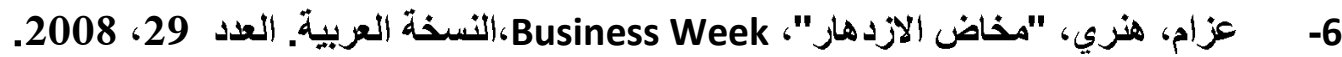
7- 1 وقائع ندوة "ظاهرة التضخم في الاقتصاد الليبي، جمعية الاقتصاديين الليبيين، الطبعة الأولى، بنغازي، 2000. 
177

1- باثا أغا، عمر، "لأثر المتبادل بين سعر الصرف وحجم الاحتياطيات الدولية في الاقتصاد الليبي"، رسالة ماجستير غير منشوزة 2009، جامعة 7 أكتوبر، ليبيا.

\section{رابعا_ ألتقاريز}

1- التثرير الأول حول التضخم في الاقتصاد الليبي ـ 2008. الهيئة العامة للمعلومات. لليبيا. 2- دصرف ليبيا المركزي، التقاريز السنوية، طر ابلس: إدارة البحوث والإحصاء، الأعداد من 1993 حتى 2008، والنشرات الاقتصادية، المجلات، من الريع الأول 2000 إلى الريع الأول 2009.

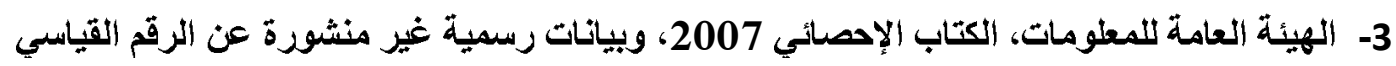

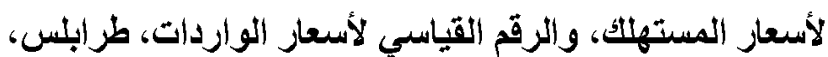

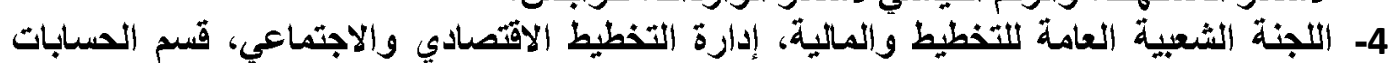
القومية، بيانات غير منشورة.

5- تقريز خبراء صندوق النقل الدولي في مشاورات عام 2008 مع ليبيا، http://www.imf.org. 